\title{
Malmquist Productivity Index by Extended VIKOR Method Using Interval Numbers
}

\author{
Mohammad Fallah,, ${ }^{1}$ Amir Mohajeri, ${ }^{2}$ and Esmaeil Najafi ${ }^{2}$ \\ ${ }^{1}$ Department of Industrial Engineering, South Tehran Branch, Islamic Azad University, Tehran 1151863411, Iran \\ ${ }^{2}$ Department of Industrial Engineering, Science and Research Branch, Islamic Azad University, Tehran 1477893855, Iran \\ Correspondence should be addressed to Amir Mohajeri; mohajeri.amir@gmail.com
}

Received 19 May 2013; Revised 27 July 2013; Accepted 7 August 2013

Academic Editor: Patricia J. Y. Wong

Copyright (c) 2013 Mohammad Fallah et al. This is an open access article distributed under the Creative Commons Attribution License, which permits unrestricted use, distribution, and reproduction in any medium, provided the original work is properly cited.

\begin{abstract}
The VIKOR method was developed for multicriteria optimization of complex systems. It determines the compromise ranking list and the compromise solution obtained with the given weights. This method focuses on ranking and selecting from a set of alternatives in the presence of conflicting criteria. Here, the VIKOR method is used for two times $t$ and $t+1$. In order to calculate the progress or regression via Malmquist productivity index, the positive and negative ideals at times $t$ and $t+1$ are calculated first. Then we introduce the multi-criteria ranking index based on the particular measure of "closeness" to the ideal solution and calculate the separation of each alternative from the ideal solution at times $t$ and $t+1$. Then we use the Malmquist productivity index to calculate the progress or regression of all alternatives. In this paper, productivity of alternatives available in decision matrix with interval numbers and their improvement or deterioration is researched. To achieve this practical goal, use of extended VIKOR is made to calculate Malmquist productivity index for multicriteria decision-making (MCDM) problem with interval numbers, and by applying Malmquist productivity index, productivity rate of growth for alternatives is calculated. Finally, a numerical example illustrates and clarifies the main results developed in this paper.
\end{abstract}

\section{Introduction}

Multi criteria optimization is the process of determining the best feasible solution according to the established criteria. Practical problems are often characterized by several conflicting criteria, and there may be no solution satisfying all criteria simultaneously. Thus, the solution is a set of noninferior solutions or a compromise solution according to the decision maker's preferences. The compromise solution was established by Yu [1] and Zeleny [2] for a problem with conflicting criteria, and it can be helping the decision makers to reach a final solution. The compromise solution is a feasible solution, which is the closest to the ideal, and compromise means an agreement established by mutual concessions.

A multiattribute decision-making (MADM) problem can be defined as shown in Table 1 where $A_{1}, A_{2}, \ldots, A_{m}$ are possible alternatives among which decision makers have to choose, $C_{1}, C_{2}, \ldots, C_{n}$ are criteria with which alternative performance is measured, $f_{i j}$ is the rating of alternative $A_{i}$ with respect to criterion $C_{j}$, and $w_{j}$ is the weight of criterion $C_{j}[3-5]$.

In classical MCDM methods, the ratings and the weights of the criteria are known precisely, whereas in the real world, in an imprecise and uncertain environment, it is an unrealistic assumption that the knowledge and representation of a decision maker or expert are so precise. To describe and treat imprecise and uncertain elements present in a decision problem, fuzzy and stochastic approaches are frequently used. In the literature, in the works of fuzzy decision making, fuzzy parameters are assumed to be with known membership functions [6-12], and in stochastic decision making, parameters are assumed to have known probability distributions [1316]. However, in reality to a decision maker (DM), it is not always easy to specify the membership function or probability distribution in an inexact environment. At least in some of the cases, the use of interval numbers may serve the purpose better. An interval number can be thought as an extension of the concept of a real number [17]. 
TABLE 1: Matrix format of a MADM problem.

\begin{tabular}{lcccc}
\hline & $C_{1}$ & $C_{2}$ & $\ldots$ & $C_{n}$ \\
\hline$A_{1}$ & $f_{11}$ & $f_{12}$ & $\ldots$ & $f_{1 n}$ \\
$A_{2}$ & $f_{21}$ & $f_{22}$ & $\ldots$ & $f_{2 n}$ \\
$\vdots$ & $\vdots$ & $\vdots$ & $\vdots$ & $\vdots$ \\
$A_{m}$ & $f_{m 1}$ & $f_{m 2}$ & $\ldots$ & $f_{m n}$ \\
\hline$W=\left[w_{1}, w_{2}, \ldots, w_{n}\right]$ & & &
\end{tabular}

The TOPSIS method to solve decision-making problems with interval data has been extended by Jahanshahloo et al. [18]. Sayadi et al. [19] have extended the concept of VIKOR method to develop a methodology for solving MADM problems with interval numbers.

In this paper, we extend the concept of VIKOR method to develop a methodology for the calculation of progress or regression via Malmquist productivity index for MADM problems with interval numbers.

\section{Extended VIKOR Method for Decision- Making Problem with Interval Numbers}

As it was said in the introduction, the interval numbers are more suitable to deal with the decision-making problems in the imprecise and uncertain environment, because they are the simplest form of representing uncertainty in the decision matrix. The interval numbers require the minimum amount of information about the values of attributes. Specifying an interval for a parameter in decision matrix indicates that the parameter can take any value within the interval. Note that, the interval numbers does not indicate how probable it is to the value to be in the interval, nor does it indicate which of the many values in the interval is the most likely to occur [20]. An interval number signifies the extent of the tolerance or a region that the parameter can possibly take. An extensive research on interval mathematics and its applications can be found in [17, 21, 22]. More information about the interval numbers and its differences with other methods of representing uncertainty such as probability and fuzzy theory can be found in [23-25].

According to these facts, when determining the exact values of the attributes is difficult or impossible, it is more appropriate to consider them as interval numbers. Therefore, in the present paper, we extend the VIKOR method to calculate Malmquist productivity index for MADM problem with interval numbers. Then, applying proposed Malmquist productivity index, we calculate the progress or regression of all alternatives. To do this, we explain the extended VIKOR method for MADM problem with interval numbers proposed by Sayadi et al. [19] in the first place. Then, we introduce a new algorithm for the calculation of progress or regression via extended VIKOR and Malmquist productivity index for MADM problem with interval numbers.

Now, we suppose that a decision matrix with interval numbers has the form shown in Table 2 where $f_{i j}$ is not known exactly, and only we know that $f_{i j} \in\left[f_{i j}^{L}, f_{i j}^{U}\right], f_{i j}^{L}$,
TABLE 2: Matrix format of a MADM problem with interval data.

\begin{tabular}{lcccc}
\hline & $C_{1}$ & $C_{2}$ & $\ldots$ & $C_{n}$ \\
\hline$A_{1}$ & {$\left[f_{11}^{L}, f_{11}^{U}\right]$} & {$\left[f_{12}^{L}, f_{12}^{U}\right]$} & $\ldots$ & {$\left[f_{1 n}^{L}, f_{1 n}^{U}\right]$} \\
$A_{2}$ & {$\left[f_{21}^{L}, f_{21}^{U}\right]$} & {$\left[f_{22}^{L}, f_{22}^{U}\right]$} & $\ldots$ & {$\left[f_{2 n}^{L}, f_{2 n}^{U}\right]$} \\
$\vdots$ & $\vdots$ & $\vdots$ & $\vdots$ & $\vdots$ \\
$A_{m}$ & {$\left[f_{m 1}^{L}, f_{m 1}^{U}\right]$} & {$\left[f_{m 2}^{L}, f_{m 2}^{U}\right]$} & $\ldots$ & {$\left[f_{m n}^{L}, f_{m n}^{U}\right]$} \\
\hline \multicolumn{2}{l}{$W=\left[w_{1}, w_{2}, \ldots, w_{n}\right]$} & & &
\end{tabular}

and $f_{i j}^{U}$ are lowest and highest value of $f_{i j}$, respectively. The extended VIKOR method consists of the following steps:

(a) Determine the positive ideal solution (PIS) and negative ideal solution (NIS):

$$
\begin{aligned}
& A^{*}=\left\{f_{1}^{*}, \ldots, f_{n}^{*}\right\} \\
&=\left\{\left(\max _{i} f_{i j}^{U} \mid j \in I\right) \text { or }\left(\min _{i} f_{i j}^{L} \mid j \in J\right)\right\}, \\
& j=1,2, \ldots, n, \\
& A^{-}=\left\{f_{1}^{-}, \ldots, f_{n}^{-}\right\} \\
&=\left\{\left(\min _{i} f_{i j}^{L} \mid j \in I\right) \text { or }\left(\max _{i} f_{i j}^{U} \mid j \in J\right)\right\}, \\
& j=1,2, \ldots, n,
\end{aligned}
$$

where $A^{*}$ and $A^{-}$represent the positive ideal and the negative ideal, respectively. $I$ is associated with the benefit criteria, and $J$ is associated with the cost criteria.

(b) In this step, compute $\left[S_{i}^{L}, S_{i}^{U}\right]$ and $\left[R_{i}^{L}, R_{i}^{U}\right]$ intervals as follows:

$$
\begin{aligned}
& S_{i}^{L}=\sum_{j \in I} w_{j} \frac{\left(f_{j}^{*}-f_{i j}^{U}\right)}{\left(f_{j}^{*}-f_{j}^{-}\right)}+\sum_{j \in J} w_{j} \frac{\left(f_{i j}^{L}-f_{j}^{*}\right)}{\left(f_{j}^{-}-f_{j}^{*}\right)}, \\
& i=1,2, \ldots, m \text {, } \\
& S_{i}^{U}=\sum_{j \in I} w_{j} \frac{\left(f_{j}^{*}-f_{i j}^{L}\right)}{\left(f_{j}^{*}-f_{j}^{-}\right)}+\sum_{j \in J} w_{j} \frac{\left(f_{i j}^{U}-f_{j}^{*}\right)}{\left(f_{j}^{-}-f_{j}^{*}\right)}, \\
& i=1,2, \ldots, m, \\
& R_{i}^{L}=\max \left\{w_{j} \frac{\left(f_{j}^{*}-f_{i j}^{U}\right)}{\left(f_{j}^{*}-f_{j}^{-}\right)} \mid j \in I,\right. \\
& \left.w_{j} \frac{\left(f_{i j}^{L}-f_{j}^{*}\right)}{\left(f_{j}^{-}-f_{j}^{*}\right)} \mid j \in J\right\}, \quad i=1,2, \ldots, m, \\
& R_{i}^{U}=\max \left\{w_{j} \frac{\left(f_{j}^{*}-f_{i j}^{L}\right)}{\left(f_{j}^{*}-f_{j}^{-}\right)} \mid j \in I,\right. \\
& \left.w_{j} \frac{\left(f_{i j}^{U}-f_{j}^{*}\right)}{\left(f_{j}^{-}-f_{j}^{*}\right)} \mid j \in J\right\}, \quad i=1,2, \ldots, m,
\end{aligned}
$$


where $w_{j}$ are the weights of criteria, expressing their relative importance.

(c) Compute the interval $Q_{i}=\left[Q_{i}^{L}, Q_{i}^{U}\right] ; i=1,2, \ldots, m$, by the following relations:

$$
\begin{aligned}
Q_{i}^{L} & =v \frac{\left(S_{i}^{L}-S^{*}\right)}{\left(S^{-}-S^{*}\right)}+(1-v) \frac{\left(R_{i}^{L}-R^{*}\right)}{\left(R^{-}-R^{*}\right)}, \\
Q_{i}^{U} & =v \frac{\left(S_{i}^{U}-S^{*}\right)}{\left(S^{-}-S^{*}\right)}+(1-v) \frac{\left(R_{i}^{U}-R^{*}\right)}{\left(R^{-}-R^{*}\right)},
\end{aligned}
$$

where

$$
\begin{aligned}
S^{*}=\min _{i} S_{i}^{L}, & S^{-}=\max _{i} S_{i}^{U}, \\
R^{*}=\min _{i} R_{i}^{L}, & R^{-}=\max _{i} R_{i}^{U},
\end{aligned}
$$

where $v$ is introduced as weight of the strategy of "the majority of criteria" (or "the maximum group utility"); here suppose that $v=0.5$.

\section{Calculate Progress or Regression via Extended VIKOR and Malmquist Index for MADM Problem with Interval Numbers}

Productivity management is one of the major sources of sustainable organizational effectiveness and a systematic understanding of the factors that affecting productivity is very important. The measurement and analysis of productivity change are always a controversial topic and have enjoyed a great deal of interest among organizational researchers and practitioners.

Originally, Sten Malmquist, a Swedish economist and statistician, proposed a quantity index for measuring the standard of living for the purpose of consumption analysis [26], but later on the Malmquist index and its variations have mainly been used in the field of production analysis. However, most of these studies have concentrated on total factor productivity (TFP) measurement, although in the spirit of the original proposition, Malmquist index could be applied in other areas equally well.

In early work in this field, productivity change was explained in terms of technical change, but recently it has become widely accepted that efficiency change can also contribute to it. In this framework, the Malmquist index was first introduced in productivity literature by Caves et al. [27]. The Malmquist productivity index was introduced as a theoretical index based on Shephard's distance function (1970) and is widely developed and used in many fields. Nishimizu and Page [28] used a parametric programming approach to compute the index for the first time in the empirical context which then is further developed and popularized as an empirical index by Fare et al. [29, 30]. They decomposed productivity change into a part attributable to change of technical efficiency and technical change and used nonparametric mathematical programming models for its computation.
So, Malmquist productivity index is defined by patching together efficiency variations of each alternative and technical variation. In addition to comparing the efficiency of each alternative at present and in the past to calculate the corresponding advancement or regression, bases itself on the society transcendence movement in these two-time intervals. Meaning that in the competition, the advancement or regression of the alternatives under consideration is defined on the advancement or regression of the society transcendence. The variations of the society transcendence are called technology variations. Therefore it is possible to examine the causes of productivity change and to see whether the productivity has improved, through a more efficient use of existing technology or through technological progress. Here, the Malmquist index is defined using the distance function and used to identify productivity differences between one firm over two-time periods. To estimate technical efficiency changes and technical changes over the period in question, the decomposed Malmquist productivity index was used. According to Fare et al. [31, 32], the Malmquist productivity index between time periods $t$ and $t+1$ can be decomposed into two components and defined as

$$
\begin{aligned}
& \underbrace{M_{t, t+1}\left(y^{t}, y^{t+1}, x^{t}, x^{t+1}\right)}_{\text {M.P.I }} \\
& =\underbrace{\frac{D^{t+1}\left(y^{t+1}, x^{t+1}\right)}{D^{t}\left(y^{t}, x^{t}\right)}}_{\text {Efficiency variations }} \\
& \times \underbrace{\left[\frac{D^{t}\left(y^{t}, x^{t}\right)}{D^{t+1}\left(y^{t}, x^{t}\right)} \times \frac{D^{t}\left(y^{t+1}, x^{t+1}\right)}{D^{t+1}\left(y^{t+1}, x^{t+1}\right)}\right]^{1 / 2}}_{\text {Technology variations }},
\end{aligned}
$$

where the notation $D$ represents the distance function and the value of $M$ is the Malmquist productivity index. The term outside the brackets (efficiency variations) is a ratio of two distance functions, which measures the change in the measure of the Farell technical efficiency between period $t$ and $t+1$. The square root term (technology variations) is a measure of the technical change in the production technology. It is an indicator of the distance covered by the efficient frontier from one period to another and thus a measure of technological improvements between the periods. The term (efficiency variations) is greater than, equal to, or less than one if the producer is moving closer to, unchanging, or diverging from the production frontier, respectively. The square root term (technology variations) is greater than, equal to, or less than one when the technological best practice is improving, unchanged, or deteriorating, respectively.

In Figure 1 the calculation of Malmquist productivity index is illustrated, where a single output $y$ is produced using a single input $x$. It is assumed that the constant returns to scale (CRS) technology. The firm $A$ produces at the point $A_{1}$ in the first period and at the point $A_{2}$ in the second period. The firm $A$ is technically inefficientin the first period as the point $A_{1}$ is below the frontier for that period. In the second period the point $A_{2}$ is on the frontier and thereby firm $A$ is technically 


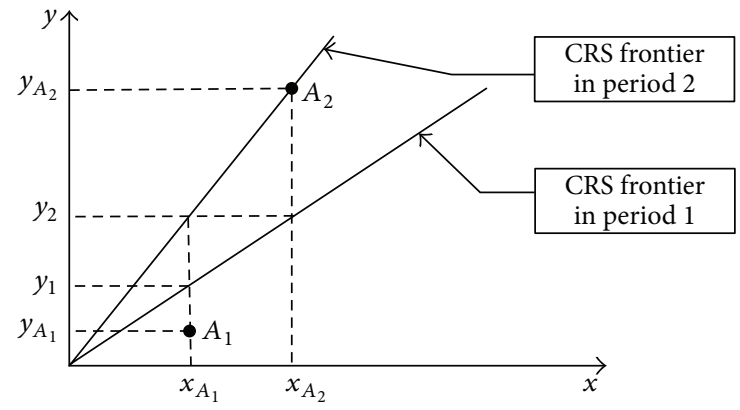

FIgURE 1: Malmquist productivity index [33].

efficient. The technical change includes a time component and involves advances in technology, which is represented by an upward shift in the production frontier from first period to the second period.

Using (5) it is

$$
\begin{aligned}
& \underbrace{M_{1,2}\left(y_{A_{1}}, y_{A_{2}}, x_{A_{1}}, x_{A_{2}}\right)}_{\text {M.P.I }} \\
& =\underbrace{\frac{y_{A_{2}} / y_{A_{2}}}{y_{A_{1}} / y_{1}}}_{\text {Efficiency variations }} \underbrace{\left[\frac{y_{A_{1}} / y_{1}}{y_{A_{1}} / y_{2}} \times \frac{y_{A_{2}} / y_{2}}{y_{A_{2}} / y_{A_{2}}}\right]^{1 / 2}}_{\text {Technology variations }} .
\end{aligned}
$$

It is easy to calculate that the value of $M$ is greater than one (i.e., $M>1$ ), which implies productivity growth. In (6) the terms efficiency variations and technology variations are also greater than one (i.e., efficiency variations $>1$ and technology variations $>1$ ). Therefore the firm $A$ experienced the positive technical efficiency change and technological change from one period to another.

Efficiency variation is the individual observations shifting relative to the best frontier (i.e., how far the average firm is from the best-practice frontier), and technology variation is the shift in the best-practice frontier. Efficiency variation above unity means that the firm has moved closer to the efficient (best-practice) frontier and thus measures "catching up" (or "falling behind" if it is less than unity). Technology variation above unity indicates technological progress, meaning that the efficient frontier has shifted out compared to the previous period, and a value below unity suggests technology regress.

As we mentioned previously, Malmquist productivity index measures the progress or regression in the period of $(t, t+1)$. If Malmquist index on the basis of minimization of production factors was less than one, it indicates productivity decrease; on the other hand, if on the basis of maximization of production factors, the Malmquist index or any of its elements were less than one, and it signifies productivity getting worse, while if the index is bigger than one, it indicates productivity improvement.

The importance of the above technique is that, in an industry occasionally, companies that have faced similar productivity decrease in an specific period of time; by evaluating productivity elements, it can be observed that productivity decrease of one company was mainly due to lack of technological advancements and nonexistence of necessary investments and for the other corporation was because of the decline of the size of activities and the limitation of productivity scale. Therefore equal decline in productivity does not signify a common reason, and it might have a specific reason for each company.

Malmquist productivity index on interval data was first introduced by Hosseinzadeh Lotfi and Ghasemi [34]. They used Data Envelopment Analysis (DEA) to calculate Malmquist productivity index and by applying Malmquist productivity index, productivity rate of growth for telecommunication companies was calculated. If the ratings of each alternative with respect to each criterion are interval, we obtained interval models. Furthermore, the value of Malmquist productivity index for each alternative will be related to one interval that the lowest and highest values of this interval have the following form:

$$
\text { M.P.I } I_{i}=\left[\text { M.P.I } I_{i}^{L} \text {, M.P.I } I_{i}^{U}\right] \text {. }
$$

In the present paper, we propose the extended VIKOR method to calculate Malmquist productivity index for MADM problem with interval numbers. Then, applying Malmquist productivity index, we calculate progress or regression of all alternatives. To do this, suppose that a decision matrix with interval data in two times of $t$ and $t+1$ has the form shown in Table 3, where $f_{i j}^{t}=\left[f_{i j}^{t, L}, f_{i j}^{t, U}\right]$ and $f_{i j}^{t+1}=\left[f_{i j}^{t+1, L}, f_{i j}^{t+1, U}\right]$ are the lowest and highest values of $f_{i j}$ in times $t$ and $t+1$, respectively (Table 3 ).

Now, use of extended VIKOR is made to calculate Malmquist productivity index for MADM problem with interval numbers. The following steps are defined as follows.

Step 1. Determine the PIS and NIS as follows:

$$
\begin{aligned}
A^{* t} & =\left\{f_{1}^{* t}, \ldots, f_{n}^{* t}\right\} \\
& =\left\{\left(\max _{i} f_{i j}^{t, U} \mid j \in I\right) \text { or }\left(\min _{i} f_{i j}^{t, L} \mid j \in J\right)\right\}, \\
A^{-t} & =\left\{f_{1}^{-t}, \ldots, f_{n}^{-t}\right\} \\
& =\left\{\left(\min _{i} f_{i j}^{t, L} \mid j \in I\right) \text { or }\left(\max _{i} f_{i j}^{t, U} \mid j \in J\right)\right\}, \\
A^{*^{t+1}} & =\left\{f_{1}^{* t+1}, \ldots, f_{n}^{* t+1}\right\}, \quad j=1,2, \ldots, n, \\
& =\left\{\left(\max _{i} f_{i j}^{t+1, U} \mid j \in I\right) \text { or }\left(\min _{i} f_{i j}^{t+1, L} \mid j \in J\right)\right\}, \\
A^{-t+1}= & \left\{f_{1}^{-t+1}, \ldots, f_{n}^{-t+1}\right\} \quad j=1,2, \ldots, n, \\
= & \left\{\left(\min _{i} f_{i j}^{t+1, L} \mid j \in I\right) \text { or }\left(\max _{i} f_{i j}^{t+1, U} \mid j \in J\right)\right\},
\end{aligned}
$$


TABLE 3: Matrix format of a MADM problem with interval data in times $t$ and $t+1$.

\begin{tabular}{ccccccccc}
\hline & & \multicolumn{1}{c}{$t$} & & & & $t+1$ & & \\
& $C_{1}$ & $C_{2}$ & $\ldots$ & $C_{n}$ & $C_{1}$ & $C_{2}$ & $\ldots$ & $C_{n}$ \\
\hline$A_{1}$ & {$\left[f_{11}^{t, L}, f_{11}^{t, U}\right]$} & {$\left[f_{12}^{t, L}, f_{12}^{t, U}\right]$} & $\ldots$ & {$\left[f_{1 n}^{t, L}, f_{1 n}^{t, U}\right]$} & {$\left[f_{11}^{t+1, L}, f_{11}^{t+U}\right]$} & {$\left[f_{12}^{t+1, L}, f_{12}^{t+1, U}\right]$} & $\ldots$ & {$\left[f_{1 n}^{t+1, L}, f_{1 n}^{t+1, U}\right]$} \\
$A_{2}$ & {$\left[f_{21}^{t, L}, f_{21}^{t, U}\right]$} & {$\left[f_{22}^{t, L}, f_{22}^{t, U}\right]$} & $\ldots$ & {$\left[f_{2 n}^{t, L}, f_{2 n}^{t, U}\right]$} & {$\left[f_{21}^{t+1, L}, f_{21}^{t+1, U}\right]$} & {$\left[f_{22}^{t+1, L}, f_{22}^{t+1, U}\right]$} & $\ldots$ & {$\left[f_{2 n}^{t+1, L}, f_{2 n}^{t+1, U}\right]$} \\
$\vdots$ & $\vdots$ & $\vdots$ & $\vdots$ & $\vdots$ & $\vdots$ & $\vdots$ & $\vdots$ & $\vdots$ \\
$A_{m}$ & {$\left[f_{m 1}^{t, L}, f_{m 1}^{t, U}\right]$} & {$\left[f_{m 2}^{t, L}, f_{m 2}^{t, U}\right]$} & $\ldots$ & {$\left[f_{m n}^{t, L}, f_{m n}^{t, U}\right]$} & {$\left[f_{m 1}^{t+1, L}, f_{m 1}^{t+1, U}\right]$} & {$\left[f_{m 2}^{t+1, L}, f_{m 2}^{t+1, U}\right]$} & $\ldots$ & {$\left[f_{m n}^{t+1, L}, f_{m n}^{t+1, U}\right]$} \\
\hline
\end{tabular}

$W=\left[w_{1}, w_{2}, \ldots, w_{n}\right]$.

where $\left(A^{* t}, A^{-t}\right)$ and $\left(A^{*^{t+1}}, A^{-t+1}\right)$ represent the positive ideal and the negative ideal in time $t$ and $t+1$, respectively.

Step 2. Compute the separation measuring. The separation of each alternative from the ideal solution is given as

$$
\begin{aligned}
& S_{i}^{(t)(t), L} \\
& =\sum_{j \in I} w_{j} \frac{\left(f_{j}^{* t}-f_{i j}^{t, U}\right)}{\left(f_{j}^{* t}-f_{j}^{-t}\right)}+\sum_{j \in J} w_{j} \frac{\left(f_{i j}^{t, L}-f_{j}^{* t}\right)}{\left(f_{j}^{-t}-f_{j}^{* t}\right)}, \\
& i=1,2, \ldots, m, \\
& S_{i}^{(t)(t), U} \\
& =\sum_{j \in I} w_{j} \frac{\left(f_{j}^{* t}-f_{i j}^{t, L}\right)}{\left(f_{j}^{* t}-f_{j}^{-t}\right)}+\sum_{j \in J} w_{j} \frac{\left(f_{i j}^{t, U}-f_{j}^{* t}\right)}{\left(f_{j}^{-t}-f_{j}^{* t}\right)}, \\
& i=1,2, \ldots, m \text {, } \\
& S_{i}^{(t+1)(t+1), L}=\sum_{j \in I} w_{j} \frac{\left(f_{j}^{* t+1}-f_{i j}^{t+1, U}\right)}{\left(f_{j}^{* t+1}-f_{j}^{-t+1}\right)} \\
& +\sum_{j \in J} w_{j} \frac{\left(f_{i j}^{t+1, L}-f_{j}^{* t+1}\right)}{\left(f_{j}^{-t+1}-f_{j}^{* t+1}\right)}, \\
& i=1,2, \ldots, m, \\
& S_{i}^{(t+1)(t+1), U}=\sum_{j \in I} w_{j} \frac{\left(f_{j}^{* t+1}-f_{i j}^{t+1, L}\right)}{\left(f_{j}^{* t+1}-f_{j}^{-t+1}\right)} \\
& +\sum_{j \in J} w_{j} \frac{\left(f_{i j}^{t+1, U}-f_{j}^{* t+1}\right)}{\left(f_{j}^{-t+1}-f_{j}^{* t+1}\right)}, \\
& i=1,2, \ldots, m, \\
& R_{i}^{(t)(t), L}=\max \left\{w_{j} \frac{\left(f_{j}^{* t}-f_{i j}^{t, U}\right)}{\left(f_{j}^{* t}-f_{j}^{-t}\right)} \mid j \in I,\right. \\
& \left.w_{j} \frac{\left(f_{i j}^{t, L}-f_{j}^{* t}\right)}{\left(f_{j}^{-t}-f_{j}^{* t}\right)} \mid j \in J\right\}, \\
& i=1,2, \ldots, m \text {, }
\end{aligned}
$$

$$
\begin{array}{r}
R_{i}^{(t)(t), U}=\max \left\{\begin{array}{r}
w_{j} \frac{\left(f_{j}^{* t}-f_{i j}^{t, L}\right)}{\left(f_{j}^{* t}-f_{j}^{-t}\right)} \mid j \in I, \\
\left.w_{j} \frac{\left(f_{i j}^{t, U}-f_{j}^{* t}\right)}{\left(f_{j}^{-t}-f_{j}^{* t}\right)} \mid j \in J\right\}, \\
i=1,2, \ldots, m,
\end{array}\right.
\end{array}
$$$$
R_{i}^{(t+1)(t+1), L}
$$$$
=\max \left\{w_{j} \frac{\left(f_{j}^{* t+1}-f_{i j}^{t+1, U}\right)}{\left(f_{j}^{* t+1}-f_{j}^{-t+1}\right)} \mid j \in I,\right.
$$$$
\left.w_{j} \frac{\left(f_{i j}^{t+1, L}-f_{j}^{* t+1}\right)}{\left(f_{j}^{-t+1}-f_{j}^{* t+1}\right)} \mid j \in J\right\},
$$$$
i=1,2, \ldots, m,
$$$$
R_{i}^{(t+1)(t+1), U}
$$$$
=\max \left\{w_{j} \frac{\left(f_{j}^{* t+1}-f_{i j}^{t+1, L}\right)}{\left(f_{j}^{* t+1}-f_{j}^{-t+1}\right)} \mid j \in I,\right.
$$$$
\left.w_{j} \frac{\left(f_{i j}^{t+1, U}-f_{j}^{* t+1}\right)}{\left(f_{j}^{-t+1}-f_{j}^{* t+1}\right)} \mid j \in J\right\},
$$$$
i=1,2, \ldots, m,
$$

where $S_{i}^{(t)(t)}=\left[S_{i}^{(t)(t), L}, S_{i}^{(t)(t), U}\right]$ and $S_{i}^{(t+1)(t+1)}=\left[S_{i}^{(t+1)(t+1), L}\right.$, $\left.S_{i}^{(t+1)(t+1), U}\right]$ represent the lowest and highest values of distance to the positive ideal and $R_{i}^{(t)(t)}=\left[R_{i}^{(t)(t), L}, R_{i}^{(t)(t), U}\right]$ and $R_{i}^{(t+1)(t+1)}=\left[R_{i}^{(t+1)(t+1), L}, R_{i}^{(t+1)(t+1), U}\right]$ represent the lowest and highest values of most inferior distance to the positive ideal, respectively, in time, $t$ and $t+1$.

Now, we have

$$
\begin{array}{r}
S_{i}^{(t)(t+1), L} \\
=\sum_{j \in I} w_{j} \frac{\left(f_{j}^{* t+1}-f_{i j}^{t, U}\right)}{\left(f_{j}^{* t+1}-f_{j}^{-t+1}\right)}+\sum_{j \in J} w_{j} \frac{\left(f_{i j}^{t, L}-f_{j}^{* t+1}\right)}{\left(f_{j}^{-t+1}-f_{j}^{* t+1}\right)}, \\
i=1,2, \ldots, m,
\end{array}
$$




$$
\begin{array}{r}
S_{i}^{(t)(t+1), U} \\
=\sum_{j \in I} w_{j} \frac{\left(f_{j}^{* t+1}-f_{i j}^{t, L}\right)}{\left(f_{j}^{* t+1}-f_{j}^{-t+1}\right)}+\sum_{j \in J} w_{j} \frac{\left(f_{i j}^{t, U}-f_{j}^{* t+1}\right)}{\left(f_{j}^{-t+1}-f_{j}^{* t+1}\right)}, \\
i=1,2, \ldots, m,
\end{array}
$$

$S_{i}^{(t+1)(t), L}$

$$
\begin{array}{r}
=\sum_{j \in I} w_{j} \frac{\left(f_{j}^{* t}-f_{i j}^{t+1, U}\right)}{\left(f_{j}^{* t}-f_{j}^{-t}\right)}+\sum_{j \in J} w_{j} \frac{\left(f_{i j}^{t+1, L}-f_{j}^{* t}\right)}{\left(f_{j}^{-t}-f_{j}^{* t}\right)}, \\
i=1,2, \ldots, m,
\end{array}
$$

$S_{i}^{(t+1)(t), U}$

$$
\begin{aligned}
& =\sum_{j \in I} w_{j} \frac{\left(f_{j}^{* t}-f_{i j}^{t+1, L}\right)}{\left(f_{j}^{* t}-f_{j}^{-t}\right)}+\sum_{j \in J} w_{j} \frac{\left(f_{i j}^{t+1, U}-f_{j}^{* t}\right)}{\left(f_{j}^{-t}-f_{j}^{* t}\right)}, \\
& i=1,2, \ldots, m, \\
& R_{i}^{(t)(t+1), L}=\max \left\{w_{j} \frac{\left(f_{j}^{* t+1}-f_{i j}^{t, U}\right)}{\left(f_{j}^{* t+1}-f_{j}^{-t+1}\right)} \mid j \in I,\right. \\
& \left.w_{j} \frac{\left(f_{i j}^{t, L}-f_{j}^{* t+1}\right)}{\left(f_{j}^{-t+1}-f_{j}^{* t+1}\right)} \mid j \in J\right\}, \\
& i=1,2, \ldots, m \text {, } \\
& R_{i}^{(t)(t+1), U}=\max \left\{w_{j} \frac{\left(f_{j}^{* t+1}-f_{i j}^{t, L}\right)}{\left(f_{j}^{* t+1}-f_{j}^{-t+1}\right)} \mid j \in I,\right. \\
& \left.w_{j} \frac{\left(f_{i j}^{t, U}-f_{j}^{* t+1}\right)}{\left(f_{j}^{-t+1}-f_{j}^{* t+1}\right)} j \in J\right\}, \\
& i=1,2, \ldots, m \text {, } \\
& R_{i}^{(t+1)(t), L}=\max \left\{w_{j} \frac{\left(f_{j}^{* t}-f_{i j}^{t+1, U}\right)}{\left(f_{j}^{* t}-f_{j}^{-t}\right)} \mid j \in I,\right. \\
& \left.w_{j} \frac{\left(f_{i j}^{t+1, L}-f_{j}^{* t}\right)}{\left(f_{j}^{-t}-f_{j}^{* t}\right)} \mid j \in J\right\}, \\
& i=1,2, \ldots, m, \\
& R_{i}^{(t+1)(t), U}=\max \left\{w_{j} \frac{\left(f_{j}^{* t}-f_{i j}^{t+1, L}\right)}{\left(f_{j}^{* t}-f_{j}^{-t}\right)} \mid j \in I,\right. \\
& \left.w_{j} \frac{\left(f_{i j}^{t+1, U}-f_{j}^{* t}\right)}{\left(f_{j}^{-t}-f_{j}^{* t}\right)} \mid j \in J\right\}, \\
& i=1,2, \ldots, m,
\end{aligned}
$$

where $S_{i}^{(t)(t+1)}=\left[S_{i}^{(t)(t+1), L}, S_{i}^{(t)(t+1), U}\right]$ represent the lowest and highest values of distance $A_{i}$ in time $t$ from the positive ideal in time $t+1$ and $S_{i}^{(t+1)(t)}=\left[S_{i}^{(t+1)(t), L}, S_{i}^{(t+1)(t), U}\right]$ represent the lowest and highest values of distance $A_{i}$ in time $t+1$ from the positive ideal in time $t$. Also, $R_{i}^{(t)(t+1)}=$ $\left[R_{i}^{(t)(t+1), L}, R_{i}^{(t)(t+1), U}\right]$ represent the lowest and highest value of most inferior distance $A_{i}$ in time $t$ from the positive ideal in time $t+1$, and $R_{i}^{(t+1)(t)}=\left[R_{i}^{(t+1)(t), L}, R_{i}^{(t+1)(t), U}\right]$ represent the lowest and highest values of most inferior distance $A_{i}$ in time $t+1$, from the positive ideal in time $t$.

Step 3. Compute the values $Q_{i}=\left[Q_{i}^{L}, Q_{i}^{U}\right], i=1,2, \ldots, m$, in forms of simple and mixed model by the following relations:

$$
\begin{aligned}
& Q_{i}^{(t)(t), L}=v \frac{\left(S_{i}^{(t)(t), L}-S^{*(t)(t)}\right)}{\left(S^{-(t)(t)}-S^{*(t)(t)}\right)} \\
& +(1-v) \frac{\left(R_{i}^{(t)(t), L}-R^{*(t)(t)}\right)}{\left(R^{-(t)(t)}-R^{*(t)(t)}\right)}, \\
& i=1,2, \ldots, m, \\
& Q_{i}^{(t)(t), U}=v \frac{\left(S_{i}^{(t)(t), U}-S^{*(t)(t)}\right)}{\left(S^{-(t)(t)}-S^{*(t)(t)}\right)} \\
& +(1-v) \frac{\left(R_{i}^{(t)(t), U}-R^{*(t)(t)}\right)}{\left(R^{-(t)(t)}-R^{*(t)(t)}\right)}, \\
& i=1,2, \ldots, m \text {, } \\
& Q_{i}^{(t+1)(t+1), L}=v \frac{\left(S_{i}^{(t+1)(t+1), L}-S^{*(t+1)(t+1)}\right)}{\left(S^{-(t+1)(t+1)}-S^{*(t+1)(t+1)}\right)} \\
& +(1-v) \frac{\left(R_{i}^{(t+1)(t+1), L}-R^{*(t+1)(t+1)}\right)}{\left(R^{-(t+1)(t+1)}-R^{*(t+1)(t+1)}\right)}, \\
& i=1,2, \ldots, m \text {, } \\
& Q_{i}^{(t+1)(t+1), U}=v \frac{\left(S_{i}^{(t+1)(t+1), U}-S^{*(t+1)(t+1)}\right)}{\left(S^{-(t+1)(t+1)}-S^{*(t+1)(t+1)}\right)} \\
& +(1-v) \frac{\left(R_{i}^{(t+1)(t+1), U}-R^{*(t+1)(t+1)}\right)}{\left(R^{-(t+1)(t+1)}-R^{*(t+1)(t+1)}\right)}, \\
& i=1,2, \ldots, m, \\
& Q_{i}^{(t)(t+1), L}=v \frac{\left(S_{i}^{(t)(t+1), L}-S^{*(t)(t+1)}\right)}{\left(S^{-(t)(t+1)}-S^{*(t)(t+1)}\right)} \\
& +(1-v) \frac{\left(R_{i}^{(t)(t+1), L}-R^{*(t)(t+1)}\right)}{\left(R^{-(t)(t+1)}-R^{*(t)(t+1)}\right)},
\end{aligned}
$$

$$
i=1,2, \ldots, m
$$




$$
\begin{aligned}
Q_{i}^{(t)(t+1), U}= & v \frac{\left(S_{i}^{(t)(t+1), U}-S^{*(t)(t+1)}\right)}{\left(S^{-(t)(t+1)}-S^{*(t)(t+1)}\right)} \\
& +(1-v) \frac{\left(R_{i}^{(t)(t+1), U}-R^{*(t)(t+1)}\right)}{\left(R^{-(t)(t+1)}-R^{*(t)(t+1)}\right)}, i=1,2, \ldots, m, \\
Q_{i}^{(t+1)(t), L}= & v \frac{\left(S_{i}^{(t+1)(t), L}-S^{*(t+1)(t)}\right)}{\left(S^{-(t+1)(t)}-S^{*(t+1)(t)}\right)} \\
& +(1-v) \frac{\left(R_{i}^{(t+1)(t), L}-R^{*(t+1)(t)}\right)}{\left(R^{-(t+1)(t)}-R^{*(t+1)(t)}\right)}, \\
Q_{i}^{(t+1)(t), U}= & v \frac{\left(S_{i}^{(t+1)(t), U}-S^{*(t+1)(t)}\right)}{\left(S^{-(t+1)(t)}-S^{*(t+1)(t)}\right)} \\
& +(1-v) \frac{\left(R_{i}^{(t+1)(t), U}-R^{*(t+1)(t)}\right)}{\left(R^{-(t+1)(t)}-R^{*(t+1)(t)}\right)}, \ldots, m, 2, \ldots, m,
\end{aligned}
$$

where

$$
\begin{aligned}
& S^{*(t)(t)}=\min _{i} S_{i}^{(t)(t), L}, S^{-(t)(t)}=\max _{i} S_{i}^{(t)(t), U}, \\
& R^{*(t)(t)}=\min _{i} R_{i}^{(t)(t), L}, R^{-(t)(t)}=\max _{i} R_{i}^{(t)(t), U}, \\
& S^{*(t+1)(t+1)}=\min _{i} S_{i}^{(t+1)(t+1), L}, S^{-(t+1)(t+1)}=\max _{i} S_{i}^{(t+1)(t+1), U}, \\
& R^{*(t+1)(t+1)}=\min _{i} R_{i}^{(t+1)(t+1), L}, \\
& R^{-(t+1)(t+1)}=\max _{i} R_{i}^{(t+1)(t+1), U}, \\
& S^{*(t)(t+1)}=\min _{i} S_{i}^{(t)(t+1), L}, S^{-(t)(t+1)}=\max _{i} S_{i}^{(t)(t+1), U}, \\
& R^{*(t)(t+1)}=\min _{i} R_{i}^{(t)(t+1), L}, R^{-(t)(t+1)}=\max _{i} R_{i}^{(t)(t+1), U}, \\
& S^{*(t+1)(t)}=\min _{i} S_{i}^{(t+1)(t), L}, S^{-(t+1)(t)}=\max _{i} S_{i}^{(t+1)(t), U}, \\
& R^{-(t+1)(t)}=\min _{i} R_{i}^{(t+1)(t), L}, R^{-(t+1)(t)}=\max _{i} R_{i}^{(t+1)(t), U} .
\end{aligned}
$$

Step 4 (Compute the Malmquist Productivity Index). There are many different methods that could be used to measure the distance function, which makes up the Malmquist productivity index. These required distance functions can be calculated using either mathematical programming or econometric techniques. The extended VIKOR method to construct Malmquist indices defining distance function based on separation measures is used in the empirical part of this study. So, the Malmquist index is defined using the proposed distance function. An alternative definition of Malmquist productivity index can be presented as the Malmquist productivity index based on separation measure of each alternative from the ideal solution in which distance and the most inferior distance to the positive ideal solution are combined $\left(Q_{i}\right)$. The distance function makes it possible to describe a multiinput, multioutput production technology and does not require the profit maximization or cost minimization assumption. So, the distance function $\left(Q_{i}\right)$ is presented as a combination of distance to the positive ideal solution $\left(S_{i}\right)$ and the most inferior distance to the positive ideal solution $\left(R_{i}\right)$. In the present paper the Malmquist productivity index will be defined using this distance function.

To define a proposed distance function, there is a sample of $M$ firms using $X^{t} \in \mathfrak{R}_{+}^{N}$ inputs and $Y^{t} \in \mathfrak{R}_{+}^{K}$ outputs in the time period $t=1, \ldots, T$. Using these inputs and outputs data, we calculate the distance and most inferior distance of each firm to the positive ideal solution, $\left(S_{i}\right)$ and $\left(R_{i}\right)$, respectively. Afterwards, $Q_{i}$ is defined as a combination of $\left(S_{i}\right)$ and $\left(R_{i}\right)$. Multiple inputs and multiple outputs production technology may be defined using the set, $P$, which represents the set of all $Q$ vectors, $Q^{t}=\left(Q_{1}^{t}, \ldots, Q_{m}^{t}\right)$, which can be produced using the $(x)$ and $(y)$ vectors, $x^{t}=\left(x_{1}^{t}, \ldots, x_{n}^{t}\right)$ and $y^{t}=\left(y_{1}^{t}, \ldots, y_{k}^{t}\right)$ in the time period $t=1, \ldots, T$. That is,

$$
\begin{array}{r}
P^{t}\left(x^{t}, y^{t}\right)=\left\{Q^{t}: x^{t}, y^{t} \text { can produce } Q^{t} \text { at time } t\right\} \\
t=1, \ldots, T .
\end{array}
$$

The proposed distance function is less than or equal to one (i.e., $Q \leq 1$ ), if and only if $Q$ belongs to the production possibility set of $x, y$ (i.e., $Q \in P(x, y)$ ). Note that the distance function is equal to the unit (i.e., $Q=1$ ), if $Q$ belongs to the "frontier" of the production possibility set. A firm is considered technically efficient if the distance function equals one.

The proposed distance function and production possibility are shown in Figure 2, where $Q_{1}$ and $Q_{2}$ are produced using $(x, y)$.

To construct the VIKOR-based Malmquist productivity index for adjacent periods and MADM problem with interval numbers, it is needed to calculate eight different proposed distance functions, $Q_{i}^{(t)(t), L}, Q_{i}^{(t)(t), U}, Q_{i}^{(t+1)(t+1), L}, Q_{i}^{(t+1)(t+1), U}$, $Q_{i}^{(t)(t+1), L}, Q_{i}^{(t)(t+1), U}, Q_{i}^{(t+1)(t), L}$, and $Q_{i}^{(t+1)(t), U}$.

In this section using the extended VIKOR method, we present an interval Malmquist productivity index. At first time we should evaluate the anti-ideal firm distance for each of time periods $t$ and $t+1$. Taking time period $t$ as the reference period, $Q_{i}^{(t)(t)}$ and $Q_{i}^{(t+1)(t)}$ are measured as proposed distance function.

Similarly, it can be seen that we can obtain the anti-ideal firm distance for time periods $t$ and $t+1$ taking time period $t+1$ as the reference period $\left(Q_{i}^{(t+1)(t+1)}\right.$ and $\left.Q_{i}^{(t)(t+1)}\right)$. 


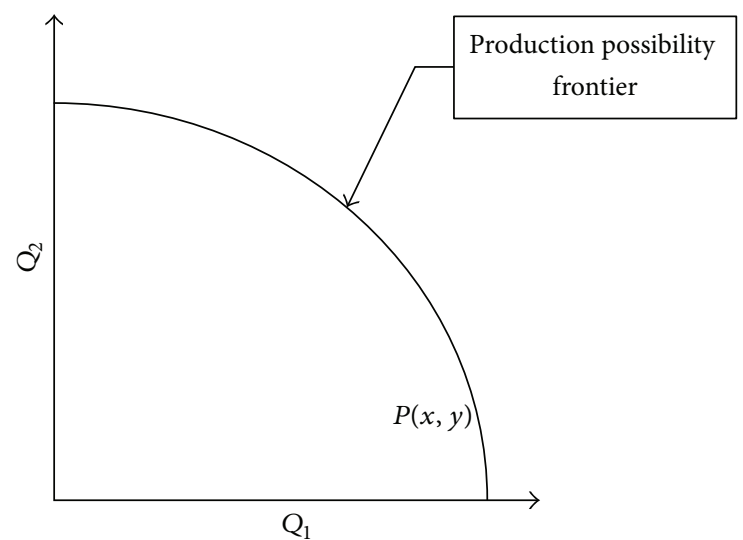

FIGURE 2: Separation-based distance function and production possibility set.

Suppose that, $Q_{i}^{(t)(t), L}$ and $Q_{i}^{(t)(t), U}$ are the lower and upper bounds of the interval $Q_{i}^{(t)(t)}$. Then distance interval is denoted by $\left[Q_{i}^{(t)(t), L}, Q_{i}^{(t)(t), U}\right]$.

Similarly, using $t+1$ instead of $t$, we get the interval distance $Q_{i}^{(t+1)(t+1)}$ as $\left[Q_{i}^{(t+1)(t+1), L}, Q_{i}^{(t+1)(t+1), U}\right]$.

The interval distance for mixed period measures is given as follows.

The interval distance for $Q_{i}^{(t+1)(t)}$ is given as $\left[Q_{i}^{(t+1)(t), L}, Q_{i}^{(t+1)(t), U}\right]$, and similarly, using $t+1$ instead of $t$, we get the interval distance for $Q_{i}^{(t)(t+1)}$ as $\left[Q_{i}^{(t)(t+1), L}, Q_{i}^{(t)(t+1), U}\right]$. We know that the Malmquist productivity index can be decomposed into two components and is defined as follows:

$$
\begin{aligned}
(5) \Longrightarrow \text { M.P.I }= & \underbrace{\frac{Q^{(t+1)(t+1)}}{Q^{(t)(t)}}}_{\text {Efficiency variations }} \\
& \times \underbrace{\left[\frac{Q^{(t)(t)}}{Q^{(t)(t+1)}} \times \frac{Q^{(t+1)(t)}}{Q^{(t+1)(t+1)}}\right]^{1 / 2}}_{\text {Technology variations }} .
\end{aligned}
$$

Note that we obtain an interval for each of factors in above formula. Measuring the Malmquist index as an interval for any firm, the lower and upper bounds of Malmquist productivity index are given as follows:

$$
\begin{array}{r}
\text { M.P.I }_{i}^{L}=\text { Efficiency variations }_{i}^{L} \\
\cdot \text { Technology variations }_{i}^{L}, \\
i=1,2, \ldots, m, \\
\text { M.P.I }_{i}^{U}=\text { Efficiency variations }_{i}^{U} \\
\cdot \text { Technology variations }_{i}^{U}, \\
i=1,2, \ldots, m,
\end{array}
$$

where the first component measures the change in technical efficiency. The value of efficiency variations for each alternative will be related to one interval that the lowest and highest values of this interval [Efficiency variations $s_{i}^{L}$, Efficiency variations $\left.{ }_{i}^{U}\right]$ computed as follows:

$$
\begin{aligned}
{\text { Efficiency variations } s_{i}^{L}}^{L}=\frac{Q_{i}^{(t+1)(t+1), L}}{Q_{i}^{(t)(t), U}}, \\
i=1,2, \ldots, m, \\
{\text { Efficiency variations } s_{i}^{U}}^{=}=\frac{Q_{i}^{(t+1)(t+1), U}}{Q_{i}^{(t)(t), L}}, \\
i=1,2, \ldots, m .
\end{aligned}
$$

And the second component measures the technology frontier shift between time periods $t$ and $t+1$. The value of technology variations for each alternative will be related to one interval that the lowest and highest values of this interval [Technology variations $s_{i}^{L}$, Technology variations $s_{i}^{U}$ ] computed as follows:

$$
\begin{aligned}
& \text { Technology variations }_{i}^{L}=\left[\frac{Q_{i}^{(t)(t), U}}{Q_{i}^{(t)(t+1), U}} \cdot \frac{Q_{i}^{(t+1)(t), L}}{Q_{i}^{(t+1)(t+1), L}}\right]^{1 / 2}, \\
& i=1,2, \ldots, m, \\
& \text { Technology variations }_{i}^{U}=\left[\frac{Q_{i}^{(t)(t), L}}{Q_{i}^{(t)(t+1), L}} \cdot \frac{Q_{i}^{(t+1)(t), U}}{Q_{i}^{(t+1)(t+1), U}}\right]^{1 / 2}, \\
& i=1,2, \ldots, m \text {. }
\end{aligned}
$$

Now we have

$$
\begin{aligned}
\text { M.P.I } I_{i}^{L} & =\frac{Q_{i}^{(t+1)(t+1), L}}{Q_{i}^{(t)(t), U}} \cdot\left[\frac{Q_{i}^{(t)(t), U}}{Q_{i}^{(t)(t+1), U}} \cdot \frac{Q_{i}^{(t+1)(t), L}}{Q_{i}^{(t+1)(t+1), L}}\right]^{1 / 2} \\
& =\left[\frac{Q_{i}^{(t+1)(t+1), L}}{Q_{i}^{(t)(t+1), U}} \cdot \frac{Q_{i}^{(t+1)(t), L}}{Q_{i}^{(t)(t), U}}\right]^{1 / 2}, \\
\text { M.P.I } I_{i}^{U} & =\frac{Q_{i}^{(t+1)(t+1), U}}{Q_{i}^{(t)(t), L}} \cdot\left[\frac{Q_{i}^{(t)(t), L}}{Q_{i}^{(t)(t+1), L}} \cdot \frac{Q_{i}^{(t+1)(t), U}}{Q_{i}^{(t+1)(t+1), U}}\right]^{1 / 2} \\
& =\left[\frac{Q_{i}^{(t+1)(t+1), U}}{Q_{i}^{(t)(t+1), L}} \cdot \frac{Q_{i}^{(t+1)(t), U}}{Q_{i}^{(t)(t), L}}\right]^{1 / 2},
\end{aligned}
$$

Describing Interval Malmquist Productivity Index. For describing the interval M.P.I, the following relations are considered:

(1) If M.P.I $I_{i}^{L}=$ M.P.I $I_{i}^{U}=1$, then Alternative ${ }_{i}$ did not have progress and regression. 


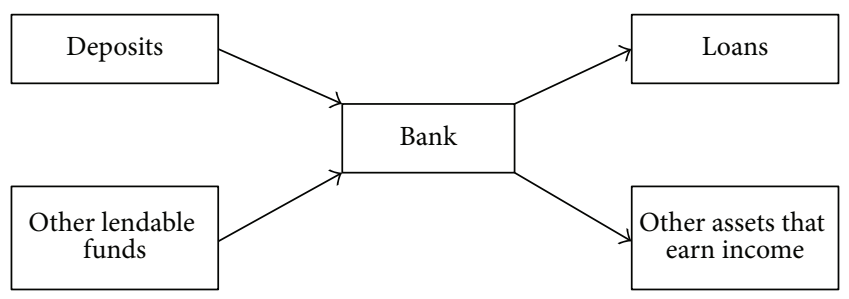

FIGURE 3: Intermediation model.

(2) If M.P.I ${ }_{i}^{L}=1$, M.P.I $I_{i}^{U}>1$, then Alternative ${ }_{i}$ did have progress.

(3) If M.P.I $I_{i}^{L}<1$, M.P.I $I_{i}^{U}=1$, then Alternative ${ }_{i}$ did have regression.

(4) If M.P. $I_{i}^{L}<1$, M.P.I $I_{i}^{U}>1$, then $\rho$ is applied to determine the progress or regression for Alternative ${ }_{i}$ as shown in

$$
\rho=\frac{\text { M.P.I } I_{i}^{U}-1}{1-\text { M.P.I } I_{i}^{L}}, \quad 0<\rho<\infty .
$$

(i) If $\rho>1$, then the percent of progress is more than the regression.

(ii) If $\rho<1$, then the percent of regression is more than the progress.

\section{Numerical Example}

In this section, we intend to apply the above proposed model to validate and verify our methodology in one illustration example. In this study, we consider ten bank branches of decision maker with respect to their performance in twotime periods (2004-2005). Also, we gather and analyze the efficient indices that can be influence on their efficiency. The exact definition of input and output variables in banking is a disputable issue [35]. There are two main approaches to the choice of how to measure the flow of services provided by banks. The majority of banking studies can be categorized as users of the intermediation model or of the production model. The intermediation approach characterizes banks as financial intermediaries whose function is to collect funds in the form of deposits and other lendable funds and to offer them as loans or other assets that earn income (Figure 3). With this approach, the data is typically assumed to be in the numbers of dollars of loans, deposits, or insurance in force [36].

Under the alternative production approach, banks are the institutions providing fee-based products and services to customers. Products and services such as loans and deposits are outputs in this model, and the resource consumed such as labour, capital, and operating expenses are inputs (Figure 4). Under this approach, output is best measured by the number and type of transactions or documents processed over a given time period $[35,37]$.

These two approaches, production and intermediation approachs have both advantage and disadvantages and cannot fully capture the role of banks. The selection of model,

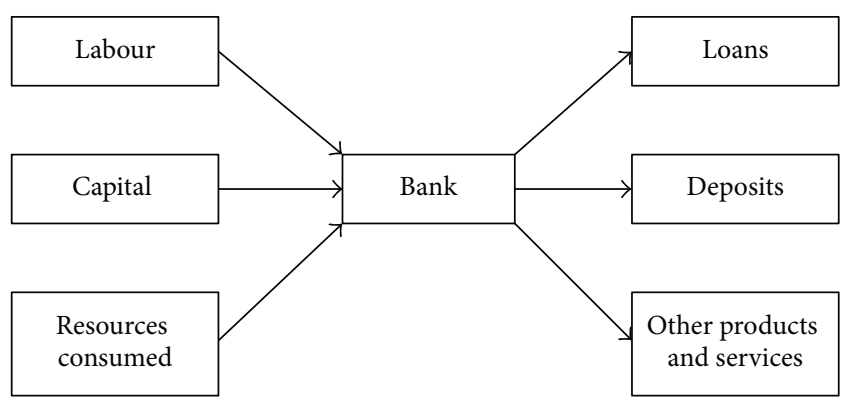

FIGURE 4: Production model.

input, and output data is essential because they have a direct influence on the results of empirical analysis. The final choice of model depends upon the concept of what banks do, the stated problem, and the availability of data. Here, the second model, production approach, is chosen to capture the role of banks.

4.1. Data. The purpose of this section is to present the empirical variable of banks in Iran and to describe the choice procedure of data for modeling. The data used in this study covers two-time periods (2004-2005). This data is from annual balance sheets and income statements of the banks involved.

The Central Bank of Iran has regularly collected the public reports by individual banks. This data was used as a database for the present paper. All variables, with the exception of number of customer and number of personnel, are reported in billions of Rials (Iranian currency unit) and corrected to the 2004 price level using the consumer price index. The example includes ten domestic branches of a commercial bank operating in Iran.

To evaluate the productivity performance of bank branches in Iran, the essential element is the selection of variables. The first selection of model variables was on the basis of the research aim, which focuses on productivity of bank branches performance and on the availability of data. Here, we select eight possible groups of data for the productivity model. They are as follows:

(i) loan to customers;

(ii) deposits from customers;

(iii) commissions received;

(iv) incomes;

(v) liabilities/deposits to credit institutions;

(vi) total costs;

(vii) number of personnel;

(viii) number of customers.

These data groups, with the exception of personnel and customers, are from the bank branches balance sheets and income statements. For each essay/model six variables were selected. The selection was made on the basis of correlation matrix. The correlation matrix displays the correlation coefficient between the variables. 
TABLE 4: Correlation matrix for the variables.

\begin{tabular}{|c|c|c|c|c|c|c|c|c|}
\hline & $\begin{array}{l}\text { Loan to } \\
\text { customers }\end{array}$ & $\begin{array}{c}\text { Deposits from } \\
\text { customers }\end{array}$ & $\begin{array}{c}\text { Commissions } \\
\text { received }\end{array}$ & Incomes & $\begin{array}{l}\text { Liabilities/deposits to } \\
\text { credit institutions }\end{array}$ & $\begin{array}{l}\text { Total } \\
\text { costs }\end{array}$ & $\begin{array}{c}\text { Number of } \\
\text { personnel }\end{array}$ & $\begin{array}{l}\text { Number of } \\
\text { customers }\end{array}$ \\
\hline Loan to customers & 1 & & & & & & & \\
\hline Deposits from customers & 0.96 & 1 & & & & & & \\
\hline Commissions received & 0.68 & 0.65 & 1 & & & & & \\
\hline Incomes & 0.75 & 0.81 & 0.32 & 1 & & & & \\
\hline $\begin{array}{l}\text { Liabilities/deposits to } \\
\text { credit institutions }\end{array}$ & 0.86 & 0.73 & 0.63 & 0.53 & 1 & & & \\
\hline Total costs & 0.70 & -0.48 & -0.36 & 0.53 & -0.42 & 1 & & \\
\hline Number of personnel & 0.93 & 0.87 & 0.51 & 0.72 & 0.79 & 0.81 & 1 & \\
\hline Number of customers & -0.7 & 0.88 & 0.52 & 0.69 & 0.77 & 0.48 & 0.91 & 1 \\
\hline
\end{tabular}

Various goals of bank performance can be presented. For instance, the bank is devoted to increasing employee motivation, while only dedicated employees can create value to bank customers and thus to bank shareholders. For selection of variables it was presumed that the goal of bank performance is to receive income. Therefore, the first step in correlation analysis was to determine the relationship between income and other rations. The data is represented in Table 4.

The strongest correlation appeared between income and the following variables: loan to customers (0.75), deposits from customers (0.81), total costs (0.65), number of personnel (0.72), and number of customers (0.69). Table 4 shows remarkably weak correlation between income and the following data set: commission received (0.32) and liabilities/deposits to credit institutions (0.53). Based on weak correlation, these are excluded from the data of the productivity model.

Based on correlation analysis results, we have selected the variables for productivity analysis for the present paper. In the first essay the production approach was used, and the variables were defined as follows.

(i) As a benefit criteria, $C_{1}$ are incomes, $C_{2}$ are the loans, $C_{3}$ are the deposits, and $C_{4}$ are the numbers of customers.

(ii) As a cost criteria, $C_{5}$ are the numbers of personnel, and $C_{6}$ are the total costs.

Our decision matrix is founded over data of ten branches of a commercial bank in Iran. Hereby, there were two-time periods between December 31, 2003, and December, 312005. Tables 8 and 9 contain some information on the variables used. Note that, the values of decision matrix are not precise, and interval numbers are used to describe and treat the uncertainty of the decision problem.

In this example, six known variables have relative importance weights $w_{i}>0, \sum_{i=1}^{6} w_{i}=1$, that can be calculated by the following steps.

Step 1 (Design an Expert Questionnaire). The fixed weights related to the variables are calculated based on expert opinion. In this way, we design a questionnaire with aim to provide an information profile of the expert which allows his/her diagnosis in determining of relative importance of variables with respect to productivity performance of bank branches. The data which is captured by the questionnaire represents all the information we have about an expert in order to calculate importance weights. The questionnaire consists of 6 questions to which the expert responds on a five-point scale (very low, low, medium, high, and very high). A sample of the filled up proposed questionnaire to determine the importance weights of the variables is given in Table 5. The bank branches employees (office employee with diploma, experts, supervisors, middle and top managers, and faculty members) are the members of statistical population of this research. For this purpose 65 questionnaires were distributed and 50 questionnaires were returned with responses.

Step 2 (Group Integration). After the polling process, we can obtain the weights of each variable. By using the semantics (Table 6), we can transform these into corresponding fuzzy numbers which were introduced by Zadeh [38] to deal with vague, imprecise and uncertain problems and have been used as a modeling tool for complex systems that can be controlled by humans but hard to define precisely.

In this paper, we use triangular fuzzy numbers for the semantic statements based on Chen and Hwangs' scaled conversion measurement [39]; see Figure 6 and Table 6. Triangular fuzzy number is a special kind of fuzzy sets. A triangular fuzzy number can be denoted as $N=(a, b, c)$. This representation is interpreted as membership functions and holds the following conditions:

(i) $a$ to $b$ is increasing function;

(ii) $b$ to $c$ is decreasing function;

(iii) $a \leq b \leq c$.

Figure 5 is an illustration of the membership function of a triangular fuzzy number. 
TABLE 5: A sample of filled up questionnaire.

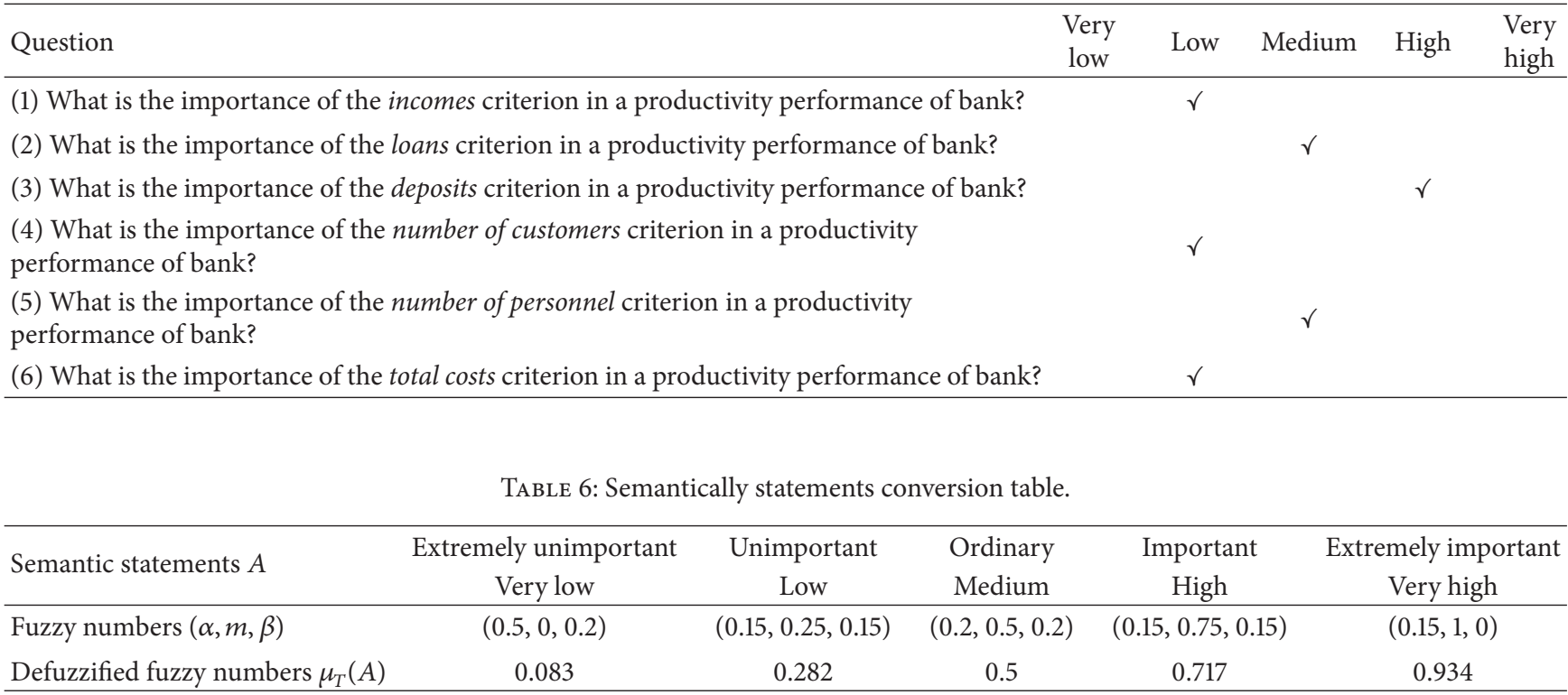

TABLE 7: Importance weights related to the six known criteria.

\begin{tabular}{lccccccc}
\hline & Very low & Low & Medium & High & Very high & Score \\
$\mu_{T}=0.083$ & $\mu_{T}=0.282$ & $\mu_{T}=0.5$ & $\mu_{T}=0.717$ & $\mu_{T}=0.934$ & $w$ \\
\hline$C_{1}$ & 13 & 10 & 10 & 5 & 12 & 0.47 & $0.1715 \cong 0.17$ \\
$C_{2}$ & 6 & 5 & 10 & 12 & 17 & 0.63 & $0.229 \cong 0.23$ \\
$C_{3}$ & 9 & 10 & 6 & 13 & 5 & 0.54 & $0.197 \cong 0.2$ \\
$C_{4}$ & 18 & 10 & 10 & 3 & 2 & 0.38 & $0.1386 \cong 0.14$ \\
$C_{5}$ & 22 & 12 & 11 & 5 & 0.29 & $0.105 \cong 0.1$ \\
$C_{6}$ & 13 & 13 & 10 & 5 & 0.43 & $0.1569 \cong 0.16$ \\
\hline
\end{tabular}

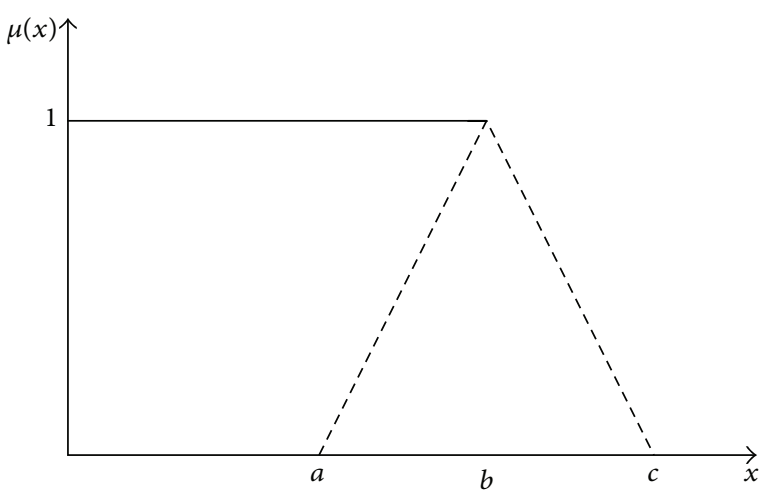

FIgURE 5: Triangular fuzzy number.

The membership function of triangular fuzzy number is

$$
\mu(x)= \begin{cases}\frac{x-a}{b-a} & \text { if } a \leq x \leq b, \\ \frac{c-x}{c-b} & \text { if } b \leq x \leq c, \\ 0 & \text { else. }\end{cases}
$$

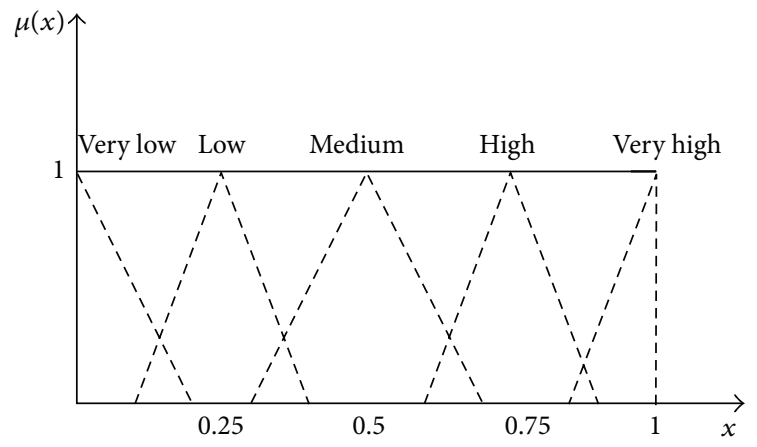

FIGURE 6: The relationship between semantic statements and fuzzy numbers.

Step 3 (Calculate the Variables' Weights). First, we defuzzify the fuzzy numbers related to the semantic statements according to (21) and report them as a membership function $\left(\mu_{T}(A)\right)$ in Table 6 . After the completed questionnaires have been returned, the frequency analysis of the results for each variable with respect to the five-point scale was done and is reported in Table 7. Afterwards, based on these findings, we calculate the score of each variable according to (22) and 
TABLE 8: Interval decision matrix in the first-time period (year of 2004).

\begin{tabular}{|c|c|c|c|c|c|c|}
\hline & $C_{1}$ & $\mathrm{C}_{2}$ & $C_{3}$ & $C_{4}$ & $C_{5}$ & $C_{6}$ \\
\hline$B_{1}$ & {$[7041,7841]$} & {$[40003.8,50003.8]$} & {$[3935,5335]$} & {$[740,840]$} & {$[7,11]$} & {$[3352,4352]$} \\
\hline$B_{2}$ & {$[1464,2264]$} & {$[31346,41346]$} & {$[2998,4398]$} & {$[321,421]$} & {$[9,13]$} & {$[1425,2425]$} \\
\hline$B_{3}$ & {$[4538,5338]$} & {$[55029.56,62029.56]$} & {$[2022,3422]$} & {$[377,477]$} & {$[13,17]$} & {$[713,1713]$} \\
\hline$B_{4}$ & {$[116535,117335]$} & {$[515090.2,52509.02]$} & {$[19317,20717]$} & {$[1069,1169]$} & {$[8,12]$} & {$[2167,3167]$} \\
\hline$B_{5}$ & {$[8122,8922]$} & {$[36655.05,46655.05]$} & {$[7973,9373]$} & {$[608,708]$} & {$[9,13]$} & {$[1350,2350]$} \\
\hline$B_{6}$ & {$[1659,2459]$} & {$[15664.4,25664.4]$} & {$[2189,3589]$} & {$[440,540]$} & {$[7,11]$} & {$[1429,2429]$} \\
\hline$B_{7}$ & {$[3562,4362]$} & {$[27000.5,37000.5]$} & {$[1903,3303]$} & {$[306,406]$} & {$[8,12]$} & {$[693,1693]$} \\
\hline$B_{8}$ & {$[51887,52687]$} & {$[887196.2,897196]$} & {$[30284,31684]$} & {$[470,570]$} & {$[15,19]$} & {$[4523,5523]$} \\
\hline$B_{9}$ & {$[6139,6939]$} & {$[48326.2,58326.2]$} & {$[4234,5634]$} & {$[361,461]$} & {$[3,7]$} & {$[1265,2265]$} \\
\hline$B_{10}$ & {$[885,1685]$} & {$[20969.35,30969.35]$} & {$[2965,4365]$} & {$[172,272]$} & {$[5,9]$} & {$[811,1811]$} \\
\hline
\end{tabular}

TABLE 9: Interval decision matrix in the second-time period (year of 2005).

\begin{tabular}{|c|c|c|c|c|c|c|}
\hline & $C_{1}$ & $\mathrm{C}_{2}$ & $C_{3}$ & $\mathrm{C}_{4}$ & $C_{5}$ & $\mathrm{C}_{6}$ \\
\hline$B_{1}$ & {$[7251,8051]$} & {$[44563.8,54563.8]$} & {$[4935,6335]$} & {$[752,852]$} & {$[8,12]$} & {$[2352,3352]$} \\
\hline$B_{2}$ & {$[1484,2284]$} & {$[33516,43516]$} & {$[2499,3899]$} & {$[421,521]$} & {$[11,15]$} & {$[1225,2225]$} \\
\hline$B_{3}$ & {$[3658,4458]$} & {$[53125.99,63125.99]$} & {$[1302,2702]$} & {$[417,517]$} & {$[11,15]$} & {$[1113,2113]$} \\
\hline$B_{4}$ & {$[130793,131593]$} & {$[480171.2,580171.2]$} & {$[19520,20920]$} & {$[1269,1369]$} & {$[9,13]$} & {$[3664,2664]$} \\
\hline$B_{5}$ & {$[7622,8422]$} & {$[37934.05,47934.05]$} & {$[8248,9648]$} & {$[628,738]$} & {$[9,13]$} & {$[1223,2223]$} \\
\hline$B_{6}$ & {$[1759,2559]$} & {$[16936.4,26936.4]$} & {$[1629,3029]$} & {$[435,535]$} & {$[5,9]$} & {$[823,1823]$} \\
\hline$B_{7}$ & {$[3108,3908]$} & {$[31132.3,41132.3]$} & {$[2213,3613]$} & {$[254,354]$} & {$[9,13]$} & {$[1073,2073]$} \\
\hline$B_{8}$ & {$[54207,55007]$} & {$[890215.2,900215]$} & {$[29595,30995]$} & {$[532,632]$} & {$[11,15]$} & {$[5677,4677]$} \\
\hline$B_{9}$ & {$[6219,7019]$} & {$[58297.2,68297.2]$} & {$[4277,5677]$} & {$[387,487]$} & {$[5,9]$} & {$[1167,2167]$} \\
\hline$B_{10}$ & {$[655,1455]$} & {$[23010.35,33010.35]$} & {$[2634,4034]$} & {$[221,321]$} & {$[7,11]$} & {$[1151,2151]$} \\
\hline
\end{tabular}

TABLE 10: PIS and NIS (year of 2004).

\begin{tabular}{ccccccc}
\hline & $C_{1}$ & $C_{2}$ & $C_{3}$ & $C_{4}$ & $C_{5}$ & $C_{6}$ \\
\hline$A^{*^{t}}$ & 117335 & 897196.2 & 31684 & 1169 & 3 & 693 \\
$A^{-^{t}}$ & 885 & 15664 & 1903 & 172 & 17 & 5523 \\
\hline
\end{tabular}

TABLE 11: PIS and NIS (year of 2005).

\begin{tabular}{ccccccc}
\hline & $C_{1}$ & $C_{2}$ & $C_{3}$ & $C_{4}$ & $C_{5}$ & $C_{6}$ \\
\hline$A^{*^{t+1}}$ & 131993 & 900215 & 30995 & 1369 & 5 & 823 \\
$A^{-{ }^{t+1}}$ & 655 & 16936.4 & 1302 & 221 & 15 & 5677 \\
\hline
\end{tabular}

TABLE 12: $S$ and $R$ interval numbers (year of 2004-year of 2004).

\begin{tabular}{lcccc}
\hline & $S_{i}^{(t)(t), L}$ & $S_{i}^{(t)(t), U}$ & $R_{i}^{(t)(t), L}$ & $R_{i}^{(t)(t), U}$ \\
\hline$B_{1}$ & 0.72 & 0.81 & 0.22 & 0.22 \\
$B_{2}$ & 0.75 & 0.83 & 0.22 & 0.23 \\
$B_{3}$ & 0.74 & 0.83 & 0.22 & 0.22 \\
$B_{4}$ & 0.26 & 0.34 & 0.1 & 0.1 \\
$B_{5}$ & 0.66 & 0.75 & 0.22 & 0.23 \\
$B_{6}$ & 0.73 & 0.81 & 0.23 & 0.23 \\
$B_{7}$ & 0.73 & 0.81 & 0.22 & 0.23 \\
$B_{8}$ & 0.32 & 0.41 & 0.13 & 0.16 \\
$B_{9}$ & 0.67 & 0.76 & 0.22 & 0.22 \\
$B_{10}$ & 0.55 & 0.78 & 0.23 & 0.23 \\
\hline
\end{tabular}

TABLE 13: $S$ and $R$ interval numbers (year of 2005-year of 2005).

\begin{tabular}{lcccc}
\hline & $S_{i}^{(t+1)(t+1), L}$ & $S_{i}^{(t+1)(t+1), U}$ & $R_{i}^{(t+1)(t+1), L}$ & $R_{i}^{(t+1)(t+1), U}$ \\
\hline$B_{1}$ & 0.69 & 0.79 & 0.22 & 0.22 \\
$B_{2}$ & 0.75 & 0.85 & 0.22 & 0.22 \\
$B_{3}$ & 0.75 & 0.84 & 0.22 & 0.22 \\
$B_{4}$ & 0.25 & 0.37 & 0.08 & 0.11 \\
$B_{5}$ & 0.66 & 0.75 & 0.22 & 0.22 \\
$B_{6}$ & 0.68 & 0.78 & 0.22 & 0.23 \\
$B_{7}$ & 0.75 & 0.84 & 0.22 & 0.23 \\
$B_{8}$ & 0.38 & 0.47 & 0.13 & 0.16 \\
$B_{9}$ & 0.67 & 0.77 & 0.22 & 0.22 \\
$B_{10}$ & 0.73 & 0.83 & 0.23 & 0.23 \\
\hline
\end{tabular}

report it in Table 7. Finally, by definition of (23), we calculate the variables' weights:

$$
\begin{gathered}
\mu_{T}(A)=\frac{m+\beta}{2(1+\beta)}+\frac{m}{2(1+\alpha)}, \\
\text { Score }_{i}=\frac{\sum_{j=1}^{S} n_{j} \cdot \mu_{T}}{\sum_{j=1}^{S} n_{j}}, \\
w_{i}=\frac{\text { score }_{i}}{\sum_{i=1}^{n} \text { score }_{i}} .
\end{gathered}
$$


TABLE 14: $S$ and $R$ interval numbers (year of 2004-year of 2005).

\begin{tabular}{lcccc}
\hline & $S_{i}^{(t)(t+1), L}$ & $S_{i}^{(t)(t+1), U}$ & $R_{i}^{(t)(t+1), L}$ & $R_{i}^{(t)(t+1), U}$ \\
\hline$B_{1}$ & 0.72 & 0.82 & 0.22 & 0.22 \\
$B_{2}$ & 0.75 & 0.84 & 0.22 & 0.23 \\
$B_{3}$ & 0.76 & 0.85 & 0.22 & 0.22 \\
$B_{4}$ & 0.28 & 0.38 & 0.1 & 0.1 \\
$B_{5}$ & 0.67 & 0.76 & 0.22 & 0.22 \\
$B_{6}$ & 0.72 & 0.82 & 0.23 & 0.23 \\
$B_{7}$ & 0.73 & 0.82 & 0.22 & 0.23 \\
$B_{8}$ & 0.33 & 0.42 & 0.12 & 0.15 \\
$B_{9}$ & 0.7 & 0.75 & 0.22 & 0.22 \\
$B_{10}$ & 0.71 & 0.76 & 0.23 & 0.23 \\
\hline
\end{tabular}

TABLE 15: $S$ and $R$ interval numbers (year of 2005-year of 2004).

\begin{tabular}{lcccc}
\hline & $S_{i}^{(t+1)(t), L}$ & $S_{i}^{(t+1)(t), U}$ & $R_{i}^{(t+1)(t), L}$ & $R_{i}^{(t+1)(t), U}$ \\
\hline$B_{1}$ & 0.68 & 0.77 & 0.22 & 0.22 \\
$B_{2}$ & 0.743 & 0.83 & 0.22 & 0.23 \\
$B_{3}$ & 0.74 & 0.83 & 0.22 & 0.22 \\
$B_{4}$ & 0.31 & 0.39 & 0.08 & 0.1 \\
$B_{5}$ & 0.65 & 0.74 & 0.22 & 0.22 \\
$B_{6}$ & 0.69 & 0.78 & 0.23 & 0.23 \\
$B_{7}$ & 0.75 & 0.83 & 0.22 & 0.23 \\
$B_{8}$ & 0.36 & 0.45 & 0.13 & 0.17 \\
$B_{9}$ & 0.68 & 0.77 & 0.22 & 0.22 \\
$B_{10}$ & 0.74 & 0.83 & 0.22 & 0.23 \\
\hline
\end{tabular}

TABLE 16: $Q$ interval numbers.

\begin{tabular}{lcccc}
\hline & $Q_{i}^{(t)(t), L}$ & $Q_{i}^{(t)(t), U}$ & $Q_{i}^{(t+1)(t+1), L}$ & $Q_{i}^{(t+1)(t+1), U}$ \\
\hline$B_{1}$ & 0.87 & 0.94 & 0.83 & 0.92 \\
$B_{2}$ & 0.89 & 1 & 0.88 & 0.92 \\
$B_{3}$ & 0.88 & 0.96 & 0.88 & 0.96 \\
$B_{4}$ & 0 & 0.07 & 0 & 0.2 \\
$B_{5}$ & 0.81 & 0.93 & 0.81 & 0.88 \\
$B_{6}$ & 0.91 & 0.98 & 0.83 & 0.94 \\
$B_{7}$ & 0.87 & 0.98 & 0.88 & 0.99 \\
$B_{8}$ & 0.17 & 0.36 & 0.28 & 0.45 \\
$B_{9}$ & 0.82 & 0.90 & 0.82 & 0.9 \\
$B_{10}$ & 0.75 & 0.96 & 0.9 & 0.98 \\
\hline
\end{tabular}

In the third essay, the Malmquist indices of productivity change and their components for the production model are researched. To solve this example using the extended VIKOR method and the proposed Malmquist productivity index, we go through the following steps.

(a) The PIS and NIS in two-time periods are computed by (8) and shown in Tables 10 and 11.

(b) In this step, we compute $\left[S_{i}^{L}, S_{i}^{U}\right]$ and $\left[R_{i}^{L}, R_{i}^{U}\right]$ for two time periods using $(9)$ and (10). The result is presented in Tables 12, 13, 14, and 15.
TABLE 17: $Q$ interval numbers.

\begin{tabular}{lcccc}
\hline & $Q_{i}^{(t)(t+1), L}$ & $Q_{i}^{(t)(t+1), U}$ & $Q_{i}^{(t+1)(t), L}$ & $Q_{i}^{(t+1)(t), U}$ \\
\hline$B_{1}$ & 0.85 & 0.94 & 0.82 & 0.91 \\
$B_{2}$ & 0.87 & 0.99 & 0.88 & 1 \\
$B_{3}$ & 0.88 & 0.96 & 0.88 & 0.97 \\
$B_{4}$ & 0 & 0.09 & 0 & 0.14 \\
$B_{5}$ & 0.80 & 0.88 & 0.79 & 0.88 \\
$B_{6}$ & 0.89 & 0.97 & 0.87 & 0.95 \\
$B_{7}$ & 0.86 & 0.97 & 0.89 & 1 \\
$B_{8}$ & 0.12 & 0.31 & 0.21 & 0.43 \\
$B_{9}$ & 0.83 & 0.87 & 0.82 & 0.91 \\
$B_{10}$ & 0.88 & 0.92 & 0.88 & 1 \\
\hline
\end{tabular}

TABLE 18: Result of M.P.I and $\rho$ scale.

\begin{tabular}{lccc}
\hline & M.P.I $^{L}$ & M.P.I $^{U}$ & $\rho$ \\
\hline$B_{1}$ & 0.88 & 1.06 & 0.5 \\
$B_{2}$ & 0.88 & 1.09 & 0.75 \\
$B_{3}$ & 0.92 & 1.1 & 1.25 \\
$B_{4}$ & 0 & 0 & - \\
$B_{5}$ & 0.88 & 1.09 & 0.75 \\
$B_{6}$ & 0.87 & 1.05 & 0.38 \\
$B_{7}$ & 0.91 & 1.15 & 1.67 \\
$B_{8}$ & 0.73 & 3.08 & 7.70 \\
$B_{9}$ & 0.93 & 1.1 & 1.43 \\
$B_{10}$ & 0.95 & 1.22 & 4.4 \\
\hline
\end{tabular}

(c) We compute the $Q_{i}=\left[Q_{i}^{L}, Q_{i}^{U}\right]$ for two-time periods by (11). Now, let us suppose that $v=0.5$. The results are shown in Tables 16 and 17.

(d) Finally, with applying models (18), the Malmquist productivity index for ten bank branches is computed. For each branch, two indices of M.P.I under lower and upper bound are obtained and reported in Table 18. For example, the branch $B_{1}$ is in the worst and best condition having 0.88 and 1.06 Malmquist productivity index, respectively. Therefore, this branch has regression and progress when it is under these conditions and $\rho$ scale in (19) model is computed as follows:

$$
\rho=\frac{1.06-1}{1-0.88}=0.5 \text {. }
$$

Also, $\rho$ scale shows that the percent of regression $B_{1}$ is more than the percent of progress. Hence $\rho$ scale for other bank branches is shown in Table 18 (column 3). Five alternatives have been the percent of progress more than the percent of regression, corresponding to achieved results, the branches which have more in comparison with others are in following order.

$$
\rho B_{8}>\rho B_{10}>\rho B_{7}>\rho B_{9}>\rho B_{3} .
$$

Four alternatives $\left(B_{1}, B_{2}, B_{5}\right.$, and $\left.B_{6}\right)$ have been the percent of regression more than the percent of progress, and $B_{4}$ has been only regression. 


\section{Conclusion}

Because of the fact that determining the exact values of the attributes is difficult or impossible, it was more appropriate to consider them as interval numbers. In this paper, we extended VIKOR method to calculate Malmquist productivity index for MADM problem with interval numbers. This method introduced the multicriteria ranking index based on the particular measure of "closeness" to the ideal solution and calculated the separation of each alternative from the ideal solution at two-time periods.

Here, productivity of alternatives available in decision matrix with interval numbers and their improvement or deterioration was researched. Productivity rate of growth for alternatives was calculated by applying proposed Malmquist productivity index. Finally, effectiveness of our methodology was illustrated by a numerical example in this paper.

\section{References}

[1] P. L. Yu, "A class of solutions for group decision problems," Management Science, vol. 19, pp. 936-946, 1973.

[2] M. Zeleny, Multiple Criteria Decision Making, McGraw-Hill, New York, NY, USA, 1982.

[3] P. L. Yu, Multiple-criteria Decision Making: Concepts, Techniques, and Extensions, vol. 30, Plenum Press, New York, NY, USA, 1985.

[4] C. L. Hwang and K. Yoon, Multiple Attribute Decision Making Methods and Applications, vol. 186, Springer, Berlin, Germany, 1981.

[5] E. Triantaphyllou, Multi-Criteria Decision Making Methods: A Comparative Study, Kluwer Academic Publishers, Dordrecht, The Netherlands, 2000.

[6] H.-F. Wang, "Fuzzy multicriteria decision making-an overview," Journal of Intelligent and Fuzzy Systems, vol. 9, no. 1-2, pp. 61-83, 2000.

[7] S. J. Chen and C. L. Hwang, Fuzzy Multiple Attribute Decision Making, Springer, Berlin, Germany, 1991.

[8] R. A. Ribeiro, "Fuzzy multiple attribute decision making: a review and new preference elicitation techniques," Fuzzy Sets and Systems, vol. 78, no. 2, pp. 155-181, 1996.

[9] S. Opricovic, "Fuzzy VIKOR with an application to water resources planning," Expert Systems with Applications, vol. 38, no. 10, pp. 12983-12990, 2011.

[10] T.-C. Chu and Y. Lin, "An extension to fuzzy MCDM," Computers \& Mathematics with Applications, vol. 57, no. 3, pp. 445-454, 2009.

[11] Y. Kim and E. S. Chung, "Fuzzy VIKOR approach for assessing the vulnerability of the water supply to climate change and variability in South Korea," Applied Mathematical Modelling, 2013.

[12] C. T. Chen, W. Z. Hung, and W. Y. Zhang, "using interval-valued fuzzy vikor for cloud service provider evaluation and selection," in Proceedings of the International Conference on Business and Information, pp. 88-99, Bali, Indonesia, 2013.

[13] P. Kall and S. W. Wallace, Stochastic Programming, Wiley, Chichester, UK, 1994.

[14] J. K. Sengupta, Optimal Decision Under Uncertainty, Springer, New York, NY, USA, 1981.
[15] S. Vajda, Probabilistic Programming, Academic Press, New York, NY, USA, 1972.

[16] X. Liu, "On the methods of decision making under uncertainty with probability information," International Journal of Intelligent Systems, vol. 19, no. 12, pp. 1217-1238, 2004.

[17] R. E. Moore, Method and Application of Interval Analysis, SIAM, Philadelphia, Pa, USA, 1979.

[18] G. R. Jahanshahloo, F. H. Lotfi, and M. Izadikhah, "An algorithmic method to extend TOPSIS for decision-making problems with interval data," Applied Mathematics and Computation, vol. 175, no. 2, pp. 1375-1384, 2006.

[19] M. K. Sayadi, M. Heydari, and K. Shahanaghi, "Extension of VIKOR method for decision making problem with interval numbers," Applied Mathematical Modelling, vol. 33, no. 5, pp. 2257-2262, 2009.

[20] F. Choobineh and A. Behrens, "Use of intervals and possibility distributions in economic analysis," Journal of the Operational Research Society, vol. 43, no. 9, pp. 907-918, 1992.

[21] G. Alefeld and J. Herzberger, Introduction to Interval Computations, Academic Press, New York, NY, USA, 1983.

[22] R. B. Kearfott and V. Kreinovich, Applications of Interval Computations, Kluwer Academic Publishers, Dordrecht, The Netherlands, 1996.

[23] A. Sengupta and T. K. Pal, "Solving the shortest path problem with interval arcs," Fuzzy Optimization and Decision Making, vol. 5, no. 1, pp. 71-89, 2006.

[24] S. Tong, "Interval number and fuzzy number linear programmings," Fuzzy Sets and Systems, vol. 66, no. 3, pp. 301-306, 1994.

[25] R. Moore and W. Lodwick, "Interval analysis and fuzzy set theory," Fuzzy Sets and Systems, vol. 135, no. 1, pp. 5-9, 2003.

[26] S. Malmquist, "Index numbers and indifference surfaces," Trabajos de Estadistica, vol. 4, no. 2, pp. 209-242, 1953.

[27] D. W. Caves, L. R. Christensen, and W. E. Diewert, "The economic theory of index numbers and the measurement of input, output and productivity," Econometrica, vol. 50, pp. 1393 $1414,1982$.

[28] M. Nishimizu and J. M. Page, "Total factor productivity growth, technological progress and technical efficiency change: dimensions of productivity change in Yugoslavia, 1965-1978," Economic Journal, vol. 92, no. 368, pp. 920-936, 1982.

[29] R. Fare, S. Grosskopf, and C. A. K. Lovell, Production Frontiers, Cambridge University Press, Cambridge, UK, 1994.

[30] R. Fare, S. Grosskopf, M. Norris, and Z. Z. Zhongyang Zhang, "Productivity growth, technical progress, and efficiency change in industrialized countries," American Economic Review, vol. 84, no. 1, pp. 66-83, 1994.

[31] R. Fare, S. Grosskopf, B. Lindgren, and P. Proos, "Productivity Development in Swedish Hospitals: A Malmquist Output Index Approach," Department of Economics Discussion Paper 89-3, Southern Illinois University, Carbondale, Ill, USA, 1989.

[32] A. Charnes, W. W. Cooper, A. Y. Lewin, and L. S. Seiford, Eds., Data Envelopment Analysis: Theory, Methodology and Applications, Kluwer Academic Publisher, Amsterdam, The Netherlands, 1995.

[33] T. Coelli, D. S. P. Rao, and G. E. Battase, An Introduction to Efficiency and Productivity Analysis, Kluwer Academic Publishers, Boston, Mass, USA, 1998.

[34] F. Hosseinzadeh lotfi and M. V. Ghasemi, "Malmquist productivity index on interval data in telecommunication firms, application of data envelopment analysis," Applied Mathematical Sciences, vol. 1, no. 15, pp. 711-722, 2007. 
[35] A. N. Berger and D. B. Humphrey, "Efficiency of financial institutions: international survey and directions for future research," European Journal of Operational Research, vol. 98, no. 2, pp. 175-212, 1997.

[36] A. N. Berger and D. B. Humphrey, "The dominance of inefficiencies over scale and product mix economies in banking," Journal of Monetary Economics, vol. 28, no. 1, pp. 117-148, 1991.

[37] H. Kuussaari and J. Vesala, "The Efficiency of Finnish Banks in Producing Payment and Account Transactions," Working paper, Bank of Finland, 1995.

[38] L. A. Zadeh, "Fuzzy sets," Information and Control, no. 8, pp. 339-353, 1965.

[39] S. J. Chen and C. L. Hwang, Fuzzy Multiple Attribute Decision Making Method and Application, A State-of-the-Art Survey, Springer, New York, NY, USA, 1992. 


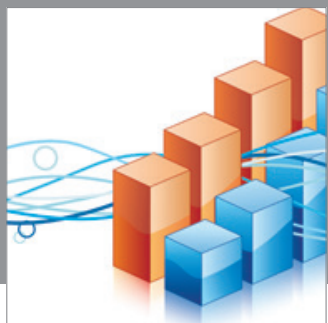

Advances in

Operations Research

mansans

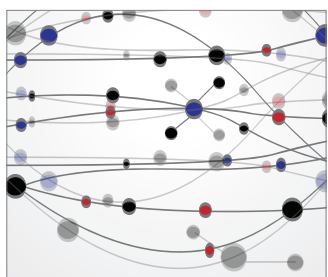

The Scientific World Journal
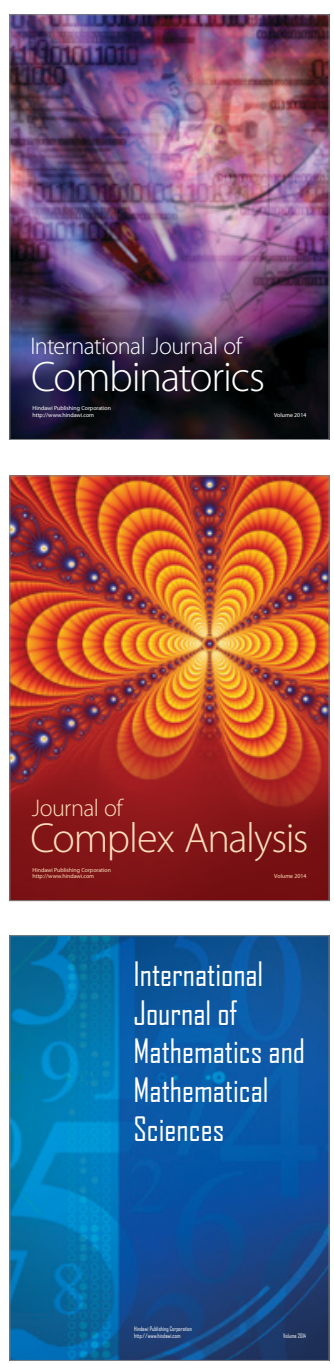
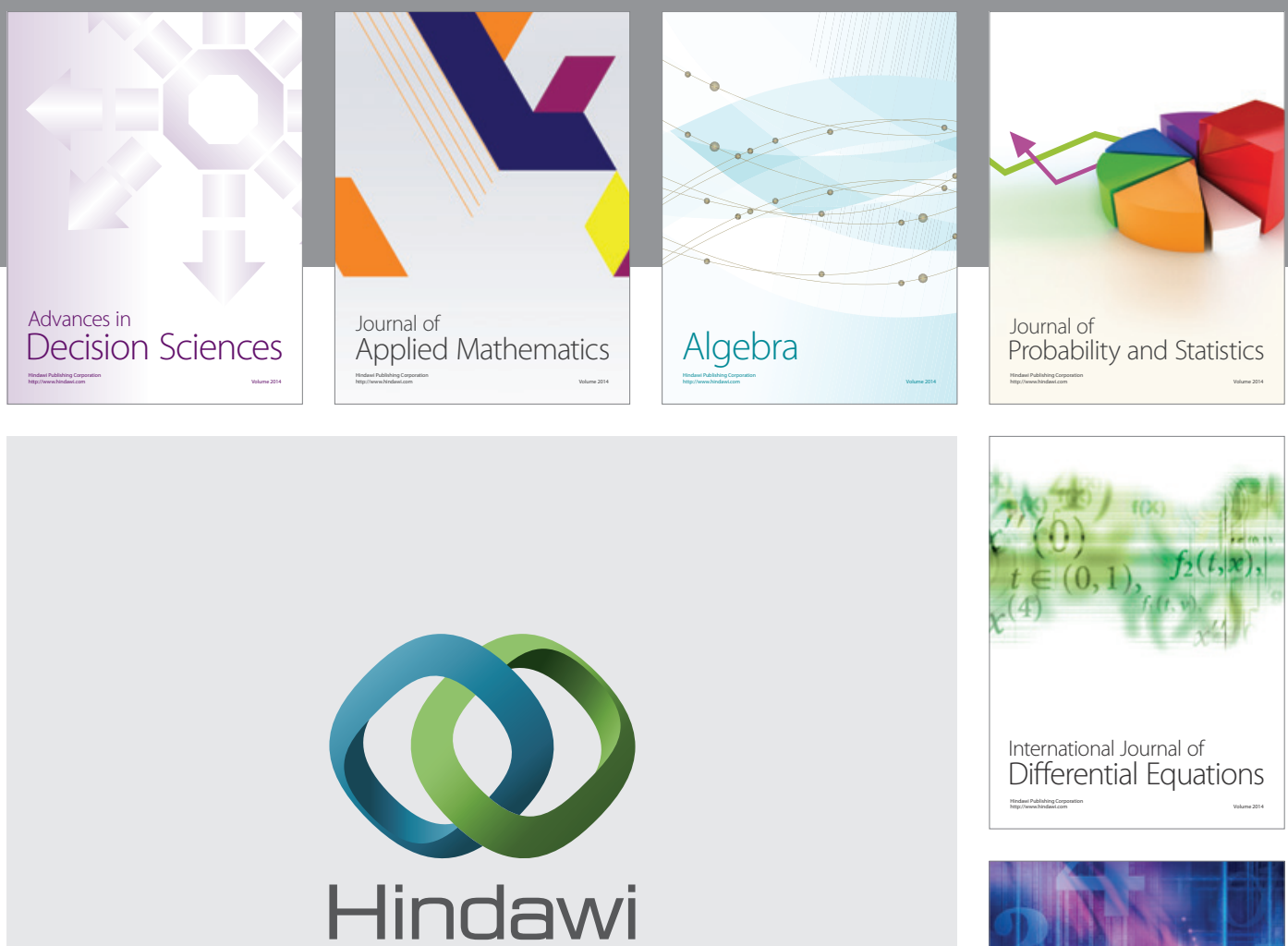

Submit your manuscripts at http://www.hindawi.com
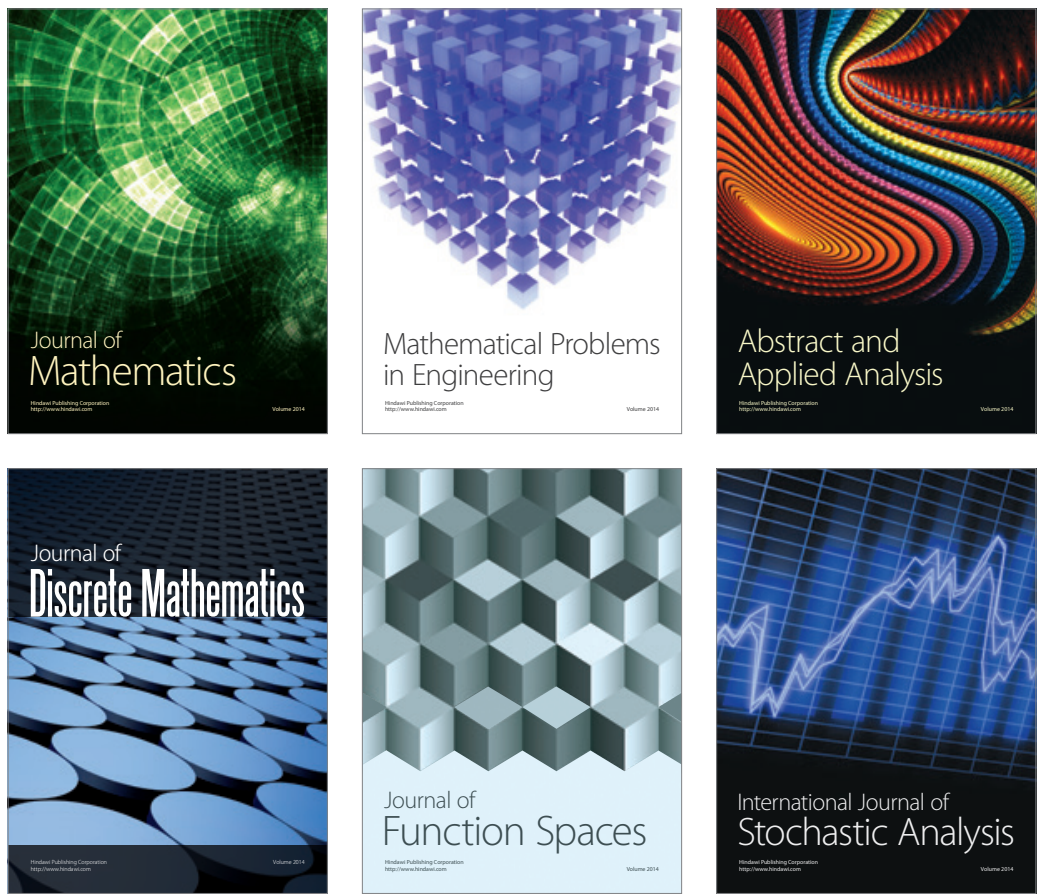

Journal of

Function Spaces

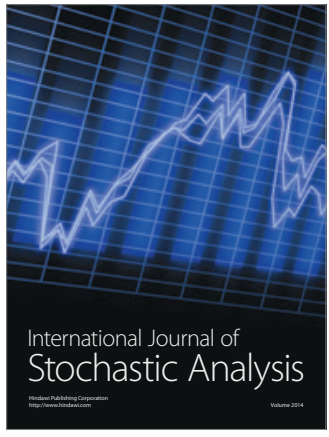

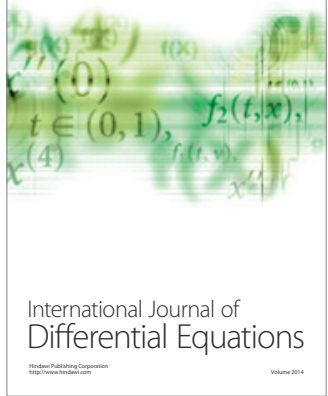
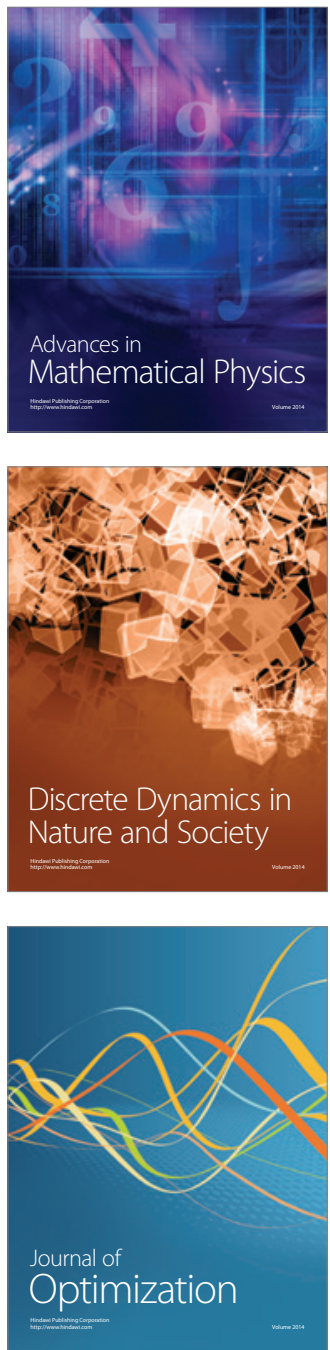